University of Rhode Island

DigitalCommons@URI

Open Access Dissertations

2014

\title{
A Population-Based Nutrition Intervention in College Students
}

Jennifer Arts

University of Rhode Island, jenarts529@gmail.com

Follow this and additional works at: https://digitalcommons.uri.edu/oa_diss

\section{Recommended Citation}

Arts, Jennifer, "A Population-Based Nutrition Intervention in College Students" (2014). Open Access

Dissertations. Paper 234.

https://digitalcommons.uri.edu/oa_diss/234

This Dissertation is brought to you for free and open access by DigitalCommons@URI. It has been accepted for inclusion in Open Access Dissertations by an authorized administrator of DigitalCommons@URI. For more information, please contact digitalcommons-group@uri.edu. 


\section{A POPULATION-BASED NUTRITION INTERVENTION \\ IN COLLEGE STUDENTS \\ BY \\ JENNIFER ARTS}

A DISSERTATION SUBMITTED IN PARTIAL FULFILLMENT OF THE

REQUIREMENTS FOR THE DEGREE OF

DOCTOR OF PHILOSOPHY

IN

BIOLOGICAL AND ENVIRONMENTAL SCIENCES

UNIVERSITY OF RHODE ISLAND

2014 
DOCTOR OF PHILOSOPHY DISSERTATION

OF

JENNIFER ARTS

APPROVED:

Dissertation Committee:

\begin{tabular}{|c|c|}
\hline \multirow[t]{4}{*}{ Major Professor } & Ingrid Lofgren \\
\hline & Cathy English \\
\hline & Matthew Delmonico \\
\hline & $\begin{array}{l}\text { Nasser H. Zawia } \\
\text { N OF THE GRADUATE SCHOOL }\end{array}$ \\
\hline
\end{tabular}




\begin{abstract}
Coronary heart disease (CHD) is a leading cause of death in young adults and at least half of college students ages 18-24 have CHD risk factor. Unhealthy dietary choices made by college students contribute to the development of CHD risk factors. Eighty-percent of heart disease is preventable through diet and lifestyle and college students are ideal targets for prevention efforts since they are in the process of establishing lifestyle habits, which track forward into adulthood. The purpose of this dissertation is to provide evidence for the need to target this age group before disease progression occurs and to present the results of a population-based intervention to increase whole grains and improve CHD factors in college students.

Manuscript 1 "Coronary Heart Disease Risk Factors in College Students" is a narrative review paper highlighting the need for improved heart disease risk assessment and awareness in college students. This review provides pathological evidence along with current risk factor prevalence data to demonstrate the need for early detection. The impact of diet is addressed and population-based strategies are presented as cost-effective ways to produce wide-scale risk reduction.

Manuscript 2 “A Population-Based Nutrition Intervention to Increase Whole Grain Intake in College Students" is a primary research paper on the impact of a nutrition messaging intervention in campus dining halls. Results indicate that a 6-week messaging intervention in campus dining halls had a positive impact on whole grain consumption and on HDL-C in college students. Future research should focus on population-based approaches on college campuses to prompt students to make healthier selections.
\end{abstract}




\section{ACKNOWLEDGMENTS}

I would like to thank each of my committee members for helping me to achieve my goal.

I have had the distinct privilege of being Dr. Ingrid Lofgren's $1^{\text {st }} \mathrm{PhD}$ student. She effectively ran "Dr. Lofgren's reform school," of which I am proud to have been a member! Her insights were endless as was her technical and emotional support. Amidst her busy schedule, she was always accessible_-days, nights and weekends. She was a sounding board and a rock I could rely on. Ingrid has a unique ability to bring out the best in you. She makes you a better you. I will be eternally grateful for her mentoring.

I am so honored to have had Dr. Cathy English on my committee. After working for her in many capacities over the years, it seems fitting that she would play a role in the final segment of my academic career. My thanks to her span my entire time at URI. Her analytical abilities and decision-making capabilities were priceless to me throughout my graduate work. I wouldn't be where I am today without Cathy.

Dr. Matt Delmonico was an indispensable core committee member. His multidisciplinary experience brought a different perspective to my research and broadened my framework of thinking. His attention to detail always kept me on track and continually improved my final products.

Dr. Geoffrey Greene can never be thanked enough for his expert input throughout my $\mathrm{PhD}$. His open door policy and statistical support were invaluable to me. Dr. Greene forces you to go one step further in your research to anticipate what 
the next question will be. He does this with an easy-going manner that keeps you balanced.

Dr. Furong Xu immediately made me feel at ease when we first met at Alton Jones. My initial impression of Dr. Xu was that she was intelligent and kind and I wanted her on my committee from that day. Thank you for making the dissertation process pleasant with your positive, assuring demeanor.

I'd also like to thank my lab mates and fellow grad students Amy Taetzsch, Liz Vandeputte, Dara LoBuono and Jess Nash who assisted me along the way with data collection. They provided me with both professional and personal support. When things got harried (as they often did), I could always count on them for early mornings, late nights and a few good laughs. Thank you all for helping me earn my doctorate! 


\section{PREFACE}

This dissertation was prepared in manuscript format.

Manuscript 1 "Coronary Heart Disease Risk Factors in College Students" is published in Advances in Nutrition (Arts J, Fernandez ML, Lofgren IE. Coronary Heart Disease Risk Factors in College Students. Adv Nutr. 2014; 5: 177-187).

Manuscript 2 "A Population-Based Nutrition Intervention to Increase Whole Grain

Intake in College Students" will be submitted to the American Journal of Health Promotion. 


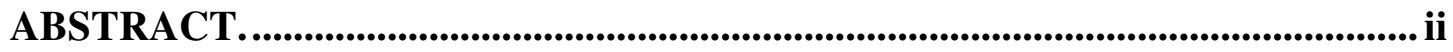

ACKNOWLEDGMENTS ...................................................................................iii

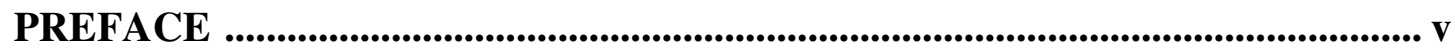

TABLE OF CONTENTS ................................................................................................... vi

LIST OF TABLES ................................................................................................... viii

LIST OF FIGURES. .............................................................................................................. ix

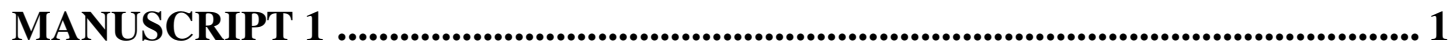

ABSTRACT ................................................................................................................. 2

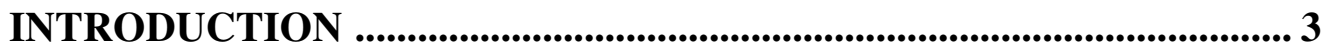

CURRENT STATUS OF KNOWLEDGE ........................................................... 5

CONCLUSIONS …................................................................................................... 23

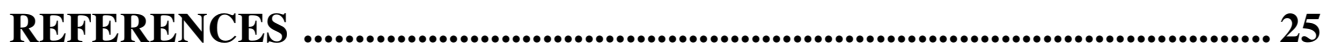

MANUSCRIPT 2.................................................................................................................... 37

ABSTRACT ............................................................................................................. 38

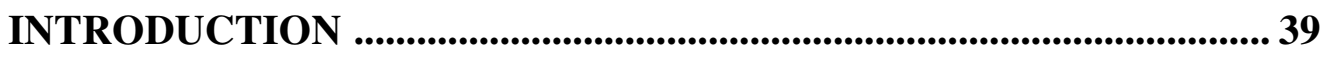

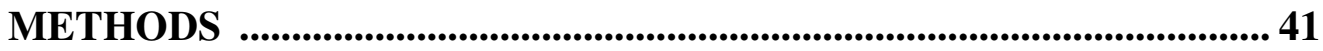

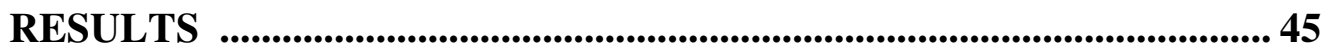

DISCUSSION .......................................................................................................... 49

REFERENCES .................................................................................................... 54

APPENDICES ............................................................................................................. 61

APPENDIX 1: EXTENDED METHODS ....................................................... 61 
APPENDIX 2: HEART START RECRUITMENT FLYER

APPENDIX 3: CONSENT FORM 75

APPENDIX 4: ASSESSMENT CHECKLIST

APPENDIX 5: INTERVENTION MESSAGES .

81 


\section{LIST OF TABLES}

TABLE

PAGE

\section{MANUSCRIPT 1}

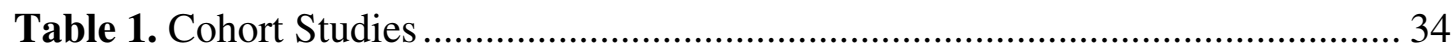

Table 2. CHD Risk Factor Prevalence in College Students .................................. 35

\section{MANUSCRIPT 2}

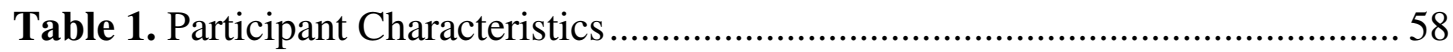

Table 2. Heart Start I Anthropometric, Biochemical, Clinical Results .................... 59 


\section{LIST OF FIGURES}

\section{FIGURE}

PAGE

MANUSCRIPT 1

Figure 1. Progression of Atherosclerosis and Prevention Targets. .......................... 36

\section{MANUSCRIPT 2}

Figure 1. Preferred Intervention Delivery Method............................................ 60 


\section{MANUSCRIPT 1}

"Coronary Heart Disease Risk Factors in College Students" is published in Advances in Nutrition.

Arts J, Fernandez ML, Lofgren IE. Coronary Heart Disease Risk Factors in College Students. Adv Nutr. 2014; 5: 177-187 


\section{Abstract:}

More than one-half of young adults ages 18-24 years have at least one coronary heart disease (CHD) risk factor and nearly one-quarter have advanced atherosclerotic lesions. The extent of atherosclerosis is directly correlated with the number of risk factors. Unhealthy dietary choices made by this age group contribute to weight gain and dyslipidemia. Risk factor profiles in young adulthood strongly predict long-term CHD risk. Early detection is critical to identify individuals at risk and to promote lifestyle changes before disease progression occurs. Despite the presence of risk factors and pathological changes, risk assessment and disease prevention efforts are lacking in this age group. The majority of young adults are not screened and are unaware of their risk. This review provides pathological evidence along with current risk factor prevalence data to demonstrate the need for early detection. Eighty-percent of heart disease is preventable through diet and lifestyle and young adults are ideal targets for prevention efforts since they are in the process of establishing lifestyle habits, which track forward into adulthood. This review aims to establish the need for increased screening, risk assessment, education and management in young adults. These essential screening efforts should include assessment of all CHD risk factors and lifestyle habits (diet, exercise and smoking), blood pressure, glucose and body mass index in addition to the traditional lipid panel for effective long-term risk reduction.

Abbreviations: CHD, coronary heart disease; CVD, cardiovascular disease; AHA, American Heart Association; NHLBI, National Heart, Lung, and Blood Institute; CDAH, Childhood Determinants of Adult Health; TC, total cholesterol; BP, blood 
pressure; LDL-C, LDL cholesterol; HDL-C, HDL cholesterol; SBP, systolic blood pressure; PDAY, Pathobiological Determinants of Atherosclerosis; cIMT, carotid artery intima media thickness; i3C, International Childhood Cardiovascular Risk Consortium; NGHS, National Heart, Lung, and Blood Institute Growth and Health Study; NHANES, National Health and Nutrition Examination Survey; WC, waist circumference; VLDL-C, VLDL cholesterol; DBP, diastolic blood pressure; American Academy of Pediatrics, AAP; US Preventive Services Task Force, USPSTF; National Cholesterol Education Program Adult Treatment Program III, NCEP ATP III; American College of Cardiology, ACC

\section{Introduction:}

Coronary heart disease (CHD) risk in young adults, ages 18-24, is underestimated despite the high prevalence of CHD risk factors (1-4) and early signs of atherosclerosis in this age group $(5,6)$. Obesity has more than doubled in children and more than tripled in adolescents over the past 30 years (7). This weight gain tracks forward and worsens in young adulthood (8). Heart disease risk increases by $2-4 \%$ for each year a young adult is obese (9). As many as 33\% of young adults are overweight (1) and this excess weight leads to dyslipidemia (10) and increases in metabolic syndrome (11), diabetes (12) and CHD (3) risk. Coronary heart disease accounts for $50 \%$ of cardiovascular disease (CVD) deaths and is one of the leading causes of death in young adults (13). Coronary heart disease costs the US $\$ 108.9$ billion each year in health care services, medications and lost productivity (14), which is more than any other disease. A death occurs from CVD every 40 seconds in the US, which would wipe out a college campus of 25,000 in less than 12 days (15). 
More than half of young adults have at least one CHD risk factor and this greatly increases lifetime heart disease risk (16). Since many CHD risk factors surface in adolescence $(13,17-19)$ and track forward to adulthood (20), the American Heart Association’s (AHA) 2020 Strategic Impact Goals along with the National Heart, Lung and Blood Institute's (NHLBI) 2012 Expert Panel on Integrated Guidelines for Cardiovascular Health and Risk Reduction in Children and Adolescents (21) emphasize primordial prevention beginning in childhood and adolescence (16). This concept of primordial prevention was introduced by Strasser in 1978 (22) and focuses on preventing the development of risk factors themselves (16). Dietary modifications are central to this approach (16).

Despite screening recommendations for all adults over age $20(23,24),<50 \%$ of women and $<40 \%$ of men of this age are screened for CHD risk (25). In addition, the majority of young adults are unaware of their risk (26). Until primordial prevention strategies are implemented to avoid risk factor development in the first place, there is a need for improved screening, risk assessment, management and education in this age group. Early detection and intervention are critical since $80 \%$ of CVD events are preventable through diet and lifestyle (27). Diets low in saturated fat and high in fruits and vegetables reduce the risk of new cardiac events by $73 \%$ (28). Despite this evidence, young adults have high intakes of solid fats, added sugars (29) and sodium $(1,30)$, along with inadequate intakes of fruits and vegetables $(31)$, whole grains $(32,33)$ and fiber (30). The AHA recently issued a scientific statement recommending reductions in added sugar intake in response to research linking sugar to excess energy intake, obesity, dyslipidemia and CHD risk (34). Sugar consumption 
has increased by nearly $20 \%$ from 1970 to 2005, supplying almost $500 \mathrm{kcal} /$ day (35). Adolescents consume more sugar than any other age group (549 kcals) (34) and this continues into young adulthood (29). Collectively, these poor dietary choices contribute to the high prevalence of CHD risk factors in this age group (36-39).

In 2011, Magnussen et al. (40) reviewed findings from two population-based studies in Finland that support the ability to avoid or delay premature atherosclerosis by prevention efforts early in life. In 2012, Rubin et al. (41) reviewed atherosclerotic versus non-atherosclerotic causes of CHD in young adults. Although these two recent reviews have examined the causes of CHD in young adults $(40,41)$, there is a need for a review of pathological evidence along with recent risk factor and screening data to highlight the need for increased screening, risk assessment, education and management in this age group.

The purpose of this review is to demonstrate the need for improved screening and risk awareness of CHD in young adults by revealing pathological changes that start in childhood and manifest themselves in young adult CHD risk factors. In addition, successful population-based prevention/treatment strategies used in other populations will be discussed with a focus on how these strategies can be applied to this age group.

\section{Current Status of Knowledge:}

\section{Progression of Atherosclerosis}

\section{Childhood Risk Factors Correlated with Extent of Lesions}

Research indicates that atherosclerosis has childhood roots. In the 1950s and 60s Holman et al., McGill et al. and Strong et al. (42-44) were the first to show that 
fatty streaks were present in the aortas of children as young as 3 years of age, without a congenital heart condition, and progressed to fibrous plaques by the second decade of life. This evidence of atherosclerosis early in life led to large, observational studies in the 1970s and 1980s $(6,45-47)$ to examine childhood CVD risk factors, lifestyle patterns and the development of CVD later in life.

The Muscatine, Bogalusa Heart, Cardiovascular Risk in Young Finns, and Childhood Determinants of Adult Health (CDAH) studies are the largest cohorts that tracked childhood risk factors into adulthood, with an average follow up time of 30 years (48) (Table 1). The Muscatine Study (1970) indicated that risk factors predictive of CHD in adulthood, such as total cholesterol (TC), TG, blood pressure (BP) and obesity, are prevalent in school-aged children (47). The Bogalusa Heart Study (1973) linked these childhood risk factors with atherosclerosis in young adults. This autopsy study showed that the extent of atherosclerotic lesions was directly correlated to antemortem levels of TC, TG, LDL cholesterol (LDL-C), HDL cholesterol (HDL-C), BP, BMI and cigarette smoking in young adults $(6,49)$. The Cardiovascular Risk in Young Finns Study (1980) provided longitudinal data to show that CHD risk factors such as TC, HDL-C, LDL-C, TG, BMI, and systolic blood pressure (SBP) track forward to adulthood $(8,45)$. Associations between childhood risk factors and those measured 27 years later were strongest for TC and LDL-C. In addition, dietary intake and patterns showed significant tracking over time as individuals in the highest quintiles of either a traditional Finnish dietary pattern or a health-conscious dietary pattern remained in the same quintile twenty-one years later (50). The CDAH study (1985) supported the findings from the previous cohort studies 
and further demonstrated that healthy lifestyle behaviors such as consuming a diet low in saturated fat and sodium and being physically active were associated with a better cardiovascular risk profile even in young adults (51). Each of these studies contributed to the understanding that early life factors influence the development of adult CVD (40).

Further evidence was provided by the Pathobiological Determinants of Atherosclerosis (PDAY) study (1987), which examined the onset and progression of atherosclerosis in over 3,000 subjects in the US ages 15-34 years (52). Although earlier autopsy studies (1970's and 80's) indicated that risk factors for CHD were associated with atherosclerosis in adults, PDAY and Bogalusa provided evidence for this in children and young adults $(6,52)$. PDAY found intimal lesions in all aortas and more than half of the right coronary arteries of adolescents ages 15-19 years (5). These lesions progress to more advanced, clinically significant lesions by young adulthood (52).

As many as $10-20 \%$ of young adults have advanced atherosclerotic lesions (53). This progression is correlated with the number of CHD risk factors; young adults with $\geq 3$ childhood risk factors had a 9-fold increase in atherosclerotic plaque area compared to those with none (6). As shown in Table 1, risk factors in childhood were shown to be strong predictors of preclinical atherosclerosis even after adjustment for adult risk factors $(54,55)$. These findings are critical from a prevention standpoint as those at risk of developing atherosclerosis can be identified and treated decades before clinical manifestation of disease. 


\section{Childhood Risk Factors Associated with Preclinical Disease Markers}

Hyperlipidemia early in life is directly related to pathologic changes and functional abnormalities and strongly predicts CHD in adulthood (56). The development of non-invasive techniques in the 1990s to measure preclinical markers such as carotid artery intima media thickness (cIMT), arterial endothelial function and coronary artery calcification allowed for the assessment of structural and functional changes indicative of preclinical atherosclerosis $(57,58)$. The Muscatine, Bogalusa Heart, Cardiovascular Disease Risk in Young Finns and CDAH studies provided evidence that these preclinical markers are associated with risk factors in childhood. Preclinical markers are strongly associated with risk of CVD events (57) but longer follow-up times are needed to directly link childhood risk factors with clinical events (40). In the absence of this data, these surrogate disease markers serve as intermediate end-points to assess the effects of risk factors and risk factor interventions before the clinical manifestation of disease and provide a better understanding of the evolution of CVD across the lifespan $(40,48)$.

In an attempt to address the difficulties in obtaining sufficient follow-up CVD events data, the International Childhood Cardiovascular Risk Consortium (i3C) was developed in 2011 to pool data previously collected from childhood to adulthood in large, multi-country cohort studies for a meta-analysis to increase the power to link longitudinal risk data with CVD events. Data from the four largest cohort studies (Muscatine, Bogalusa, Cardiovascular Disease Risk in Young Finns, and CDAH) and from similar smaller studies (Minneapolis Childhood Cohort Studies, Princeton Lipid Research Clinics Study, National Heart, Lung, and Blood Institute Growth and Health 
Study (NGHS)) were combined for a total number of 12,000 participants with major CVD risk factors measured at least once in childhood and adulthood. In an effort to determine the effects of child and adult elevated BP on cIMT, data was pooled from the Bogalusa, Muscatine, Young Finns and CDAH with a mean follow-up of 23 years. Participants were 6-18 years old at baseline and 27-45 years old at follow-up. Results indicated that elevated blood pressure that persisted from childhood into adulthood increased cIMT (59). In a similar analysis using the same four cohort studies $(\mathrm{n}=4,380$ ages 3-18 years at baseline, mean follow-up=22 years), the influence of age on the associations between childhood risk factors and cIMT in adulthood was examined (60). Risk factors (TC, TG, BMI, SBP) measured in the oldest children (15-18 year olds) at baseline were the strongest predictors of increased cIMT more than 20 years later. These findings demonstrate that late adolescence is the optimal age for screening and these screenings can effectively identify those at risk of atherosclerosis in adulthood (60).

Another recent meta-analysis (2013) on young adults from the i3C consortium (Bogalusa, Young Finns, CDAH studies) and from the Minneapolis Childhood Cohort Studies and the Princeton Follow-Up Study assessed the association of ideal cardiovascular health with cIMT (61) in 5,785 participants ages 20-38 years (61). Ideal cardiovascular health is emphasized in the AHA's 2020 Strategic Impact Goals and is defined as blood pressure $<120 / 80 \mathrm{mmHg}$, glucose $<100 \mathrm{mg} / \mathrm{dL}, \mathrm{TC}<200$ $\mathrm{mg} / \mathrm{dL}, \mathrm{BMI}<25 \mathrm{~kg} / \mathrm{m}^{2}$, physical activity $>150 \mathrm{~min} / \mathrm{wk}$ moderate/vigorous or $>75$ $\mathrm{min} / \mathrm{wk}$ vigorous, nonsmoking and 4-5 components of a healthy diet score (16). Ideal cardiovascular health was achieved by only $1 \%$ of young adults. The least commonly 
met goal was diet-related; only $7 \%$ met the criteria for ideal diet. Compliance was particularly poor for sodium intake and saturated fat intake. The number of ideal cardiovascular health criteria was inversely associated with cIMT, demonstrating that these 7 health metrics are related to vascular health in young adults. The goal of future analyses from i3C data is to determine the independent effects of childhood and early adult levels of CVD risk factors on subsequent CVD occurrence (48). This will involve collecting CVD morbidity and mortality follow-up data, examining gene variants that increase disease risk and harmonizing non-invasive vascular measures to obtain a better understanding of causal pathways to CVD events (48).

Although diet was not the main outcome in any of the studies in the i3C consortium, it was measured in all studies. Future research should involve a pooled analysis to better understand the role that dietary intake in childhood and adolescence has on present and future CVD risk. Since diet is considered the first line of defense, this research would guide the development of both population-based and individual prevention efforts.

\section{Poor Dietary Choices Negatively Impact CHD Risk Factors}

\section{Adolescents}

Unhealthy diet choices are a major determinant of CHD risk $(34,62,63)$. Recent NHANES data in 4673 adolescents ages 12-19 y show an alarmingly high prevalence of adolescents in poor and intermediate CHD risk factor categories (64). Adherence to the five components of the healthy diet score was assessed: $>4.5$ cups $\left(0.001 \mathrm{~m}^{3}\right)$ of fruits and vegetables per day, > two $3.5 \mathrm{oz}(99.2 \mathrm{~g})$ servings of fish per 
week, $>$ three $1 \mathrm{oz}(28.4 \mathrm{~g})$ servings of fiber-rich whole grains $(>1.1 \mathrm{~g}$ of fiber per $10 \mathrm{~g}$ of carbohydrate) per day, $<1500 \mathrm{mg}$ of sodium per day and $<450 \mathrm{kcals}(1884.1 \mathrm{~kJ})$ from sugar-sweetened beverages per week. Healthy diet score was the least prevalent component of ideal cardiovascular health (64). Less than $1 \%$ met the criteria for an ideal healthy diet score and $90 \%$ had diets classified as poor. Adolescents consume as much as $34 \%$ of energy intake from solid fats and added sugars (65), exceeding recommendations by over $200 \%$. Consumption of excess calories from solid fats and added sugars is a major contributor to weight gain, which increases CHD risk in a dose-response manner (66). Although not the focus of this paper, this data highlights the most prevalent dietary quality issues in this age group.

Dietary patterns established early in life carry into adulthood and are strongly associated with CHD risk (50). The transition from adolescence to young adulthood is considered a high risk period due to declines in diet quality and increases in body weight (67-69). This transition period is often marked by students entering college, living away from home for the first time and experiencing increased independence and responsibility for food choices $(67,70)$. If adolescents enter this transition period with poor diet quality, their chances of making positive dietary changes without intervention/education is slim.

\section{College Students}

College students consume excessive calories from high-fat snack foods (cookies, cake, chips, ice cream), frequently skip meals, avoid certain nutrient-dense foods (fruits, vegetables, low-fat dairy) and practice unhealthy weight-loss techniques (71-73). These unhealthy dietary choices and eating behaviors contribute to the 
declines in diet quality observed during this period. College students' diets exceed recommendations of total fat ( $46 \%$ versus $35 \%$ of energy) and saturated fat $(13 \%$ versus $10 \%$ of energy) (30). Total sugar (24\% of energy) and added sugar (17\% of energy) intake also surpass guidelines (<10\% of energy) $(29,74)$. College students also fail to meet whole grain recommendations $(32,33)$, consuming just over $10 \%$ (10.5 g) of the recommended $3 \mathrm{oz}(85.1 \mathrm{~g})$ (33). Similarly, fiber intake is inadequate with only $43 \%$ of females and $51 \%$ of males meeting recommendations (30). Over $90 \%$ of college students exceed sodium recommendations (1). Dietary patterns high in solid fats, added sugars and sodium and low in whole grains and fiber are known to exacerbate CHD risk factors $(37,62)$.

The change in the college dining environment may play an important role in the worsening of eating behaviors and dietary intake during the transition from adolescence to young adulthood (75). Most dining halls are "all-you-can-eat" styles and allow unlimited meal frequency. The campus food environment is no longer restricted to dining halls; students now have access to a variety of on campus restaurants, cafes, snack bars, convenience stores and vending machines $(76,77)$. Although there are a greater variety of options both on and off-campus, there are few healthful options $(76,78)$.

In 2012, Horacek et al. (77) assessed the on-campus and off-campus dining environment at 15 universities. Unhealthy dining environments were widespread. Fast-food restaurants had significantly greater portion sizes and were more likely to have "combo meal" pricing compared to snack bars/cafes, dining halls and other sit down, fast casual and student union dining venues. Signs to encourage unhealthy or 
overeating were most common at fast-food restaurants and at snack bars/cafes. Dining halls had significantly more healthy entrees, non-fried vegetables, no-sugar added fruit, vegetarian options, whole wheat bread and low-fat milk compared to all other dining settings. Dining halls, however, had one of biggest barriers to healthy eating: “all-you-can-eat" pricing. This "all-you-can-eat" environment and the wide variety of foods available in dining halls leads to larger portion sizes, increased energy intake and weight gain (79). In the first semester, college students gain weight up to 11 times faster compared to young adults not in college (71) and maintain this weight throughout college (80) and into adulthood. This additional weight, most of which is excess body fat, can lead to dyslipidemia and increased heart disease risk (10).

\section{Prevalence of CHD Risk Factors in College Students}

Coronary heart disease risk factors in young adulthood can be the result of pathological changes from childhood. Only $20 \%$ of CHD in young adults is related to non-atherosclerotic factors (41). Results from the few cross-sectional studies that have assessed CHD risk in college students, ages 18-24 years show an alarmingly high prevalence of young adults with abnormal risk factor profiles (Table 2). Huang et al. (81) reported that the most prevalent risk factors in a sample of 163 college students were elevated TC (12\%) and low HDL-C (14\%). Impaired glucose metabolism was also a concern as just over $6 \%$ had pre-diabetes. Overweight students had worse risk factor profiles (waist circumference (WC), BP, TC, LDL-C, VLDL cholesterol (VLDL-C), TG, leptin, insulin) compared to normal weight students and were nearly 3 times more likely to have at least one metabolic syndrome component. 
Fernandes et al. (2) assessed the prevalence of metabolic syndrome criteria in 189 first year college students and found that $18 \%$ had elevated TG and $20 \%$ had low HDL-C for gender. Metabolic syndrome risk was also high; $28 \%$ met at least one of the criteria for metabolic syndrome and $4 \%$ had metabolic syndrome. Obese students were more likely to meet 3 or more metabolic syndrome criteria and had a higher prevalence of abnormal HDL-C, WC and BP compared to subjects with a $\mathrm{BMI}<30$ $\mathrm{kg} / \mathrm{m}^{2}$. Gender differences were also noted, with males having a higher prevalence of risk factors (Table 2).

In a similar study by Huang et al. (4) that examined prevalence of metabolic risk and gender differences in a sample of 300 students, 24\% had low HDL-C, $9 \%$ had elevated fasting glucose and $9 \%$ had elevated TG. Overall prevalence of metabolic syndrome was low (1\%) but $1 / 3$ of the sample had at least one component. As shown in Table 2, males had a worse metabolic profile than females.

In a larger study performed on 1,701 college students, Burke et al. (1) reported that more than half had at least one CHD risk factor. The sample had high rates of overweight/obesity (33\%) and elevated LDL-C (53\%), TC (27\%) and BP (47\%). Males also had a worse risk factor profile (BMI, glucose, TC, HDL-C, LDL-C, SBP and diastolic blood pressure (DBP)) than females in this study. In a subsequent analysis of the same data but with a larger sample size, $(n=2,103)$ nearly $1 / 3$ had low HDL-C, nearly 2/3 had high BP and approximately 1/4 had elevated TC or LDL-C (3). Metabolic syndrome was observed in up to $10 \%$ of the sample and those with a higher BMI had a significantly greater number of individual metabolic syndrome risk factors. In addition, males had higher risk prevalence (BMI, HDL-C, LDL-C, TG, BP). 
The differences in prevalence rates across studies can be partially attributed to demographic differences between universities. Risk factor profiles can be expected to vary due to different ethnic breakdowns and lifestyle factors across geographically dispersed university samples (2). There were also gender differences; a higher prevalence of CHD risk factors was found in men. Risk factor profiles were worse in overweight and obese individuals, regardless of gender. Collectively, these studies demonstrate that dyslipidemia and metabolic dysfunction are a common and major concern in young adults. As previously discussed, poor dietary choices made by this age group contribute to the high prevalence of risk factors. These data underscore the need to identify those at risk, especially male and overweight/obese young adults, so that steps can be taken to prevent future CHD risk and manage existing risk factors. Data collected to-date demonstrates that college students are at risk for heart disease but additional research needs to be done on young adults not in college to get a more comprehensive profile of this age group.

\section{CHD Risk Factor Screening in Young Adults}

\section{Historically Conflicting Guidelines}

Data from the cross-sectional studies mentioned above demonstrate that CHD risk factor prevalence is high in this age bracket, yet universal risk assessment for primordial and primary prevention is lacking. Although the importance and need for screening for early detection and management of dyslipidemia is recognized from public health organizations, including the NHLBI, AHA, American Academy of Pediatrics (AAP), and US Preventive Services Task Force (USPSTF), the majority of 
young adults are not screened (25). The absence of apparent disease in young adults contributes to the underestimation of risk in this age group by both young adults themselves and health professionals $(26,82,83)$. This underestimation of risk and historically differing risk assessment guidelines contribute to this problem (84).

A variety of approaches and attitudes toward screening in young adults has existed among health professionals over the past two decades $(84,85)$. This can be traced back to the 1990s, with the release of the National Cholesterol Education Program Adult Treatment Panel III (NCEP ATP II) guidelines in 1993 that recommended universal lipid screening, regardless of risk level, every 5 years for all adults over age 20 years. The rationale for these recommendations was to detect individuals at risk early on so that early intervention could reduce long-term CHD risk. Although these guidelines have been endorsed by representatives from over 40 different medical and health organizations, the American College of Physicians argued against the need for screening in young adults due to the low short-term risk for CHD is this age group (86). Despite the presence of detractors early on, however, the strength of these screening recommendations was evidenced by their inclusion in 2004 NCEP ATP III Guidelines (17) and in more recent 2012 NHLBI Guidelines for Cardiovascular Health and Risk Reduction in Children and Adolescents (21) and 2013 American College of Cardiology (ACC)/AHA Guidelines on Assessment of CVD Risk (23).

Different recommendations over the past 20 years from other organizations has also led to inconsistent screening practices (84). 2008 guidelines from the USPSTF recommend screening in all men over age 35 and in men 20-35 years of age and 
women over age 45 at increased risk (87). The USPSTF makes no recommendation, however, for or against routine screening in men and women over 20 years of age who are not at increased risk of CHD and states that the optimal screening interval is uncertain. Young adults in the 18-24 year age bracket span both children/adolescent and adult recommendations, which further complicate the issue. Screening guidelines for children and adolescents have also been conflicting since 1992 due to different recommendations by the NCEP (88), AHA (89), USPSTF (90), AAP (91) and National Lipid Association (92). This conflicting guidance over the past 20 years has made it difficult for a uniform screening protocol to be followed by doctors and other health professionals (84).

Much needed progress was made, however, with the release of the 2012 NHLBI Expert Panel on Integrated Guidelines for Cardiovascular Health and Risk Reduction in Children and Adolescents (21) and the ACC/AHA Guidelines on Assessment of CVD Risk in 2013 (23). The NHLBI's comprehensive, evidence-based guidelines represent a change in approach from targeted screening to universal screening with an emphasis on primordial and primary prevention. This change was supported by the inability of previous high-risk, targeted screening approaches to detect up to $60 \%$ of children and adolescents with hypercholesterolemia (93). The 2012 evidence-based recommendations for lipid assessment recommend universal lipid screening by a non-fasting non-HDL-C level between ages 9-11 and 17-21 years of age. Targeted screening is recommended between 2-8 and 12-16 years of age if risk factors are present. These new lipid screening guidelines are endorsed by the AAP but the new expanded screening guidelines have not been without their detractors $(84,94-$ 
96). There are concerns that the new guidelines may result in over diagnosis, falsepositives, and overuse of statins in children (94-96). Although some experts disagree with the conservative nature of the guidelines, they are a pivotal step in the shift toward primordial, population-based prevention strategies that are needed to reduce future risk $(16,23,64,97,98)$.

More recent 2013 ACC/AHA CVD Assessment Guidelines also support the need for risk assessment early in life to motivate lifestyle changes in younger individuals who may be at low short-term risk but could benefit from long-term risk assessment. Long-term risk assessment of traditional CVD risk factors is recommended every 4-6 years beginning at age 20 for those who are free from atherosclerotic cardiovascular disease (23).

Inadequate Screening in Young Adults

National Health and Nutrition Examination Survey data from 1999-2006 on 2587 young adults ages $20-45$ years, indicated that $2 / 3$ have at least one CVD risk factor. This is alarming since less than $50 \%$ of females and less than $40 \%$ of males reported being screened prior to the assessment visit. The screening rate for young adults in the 18-24 year age bracket can be expected to be even lower as screening rates increase with age (99). Younger males, in particular, are more than 50\% less likely than their female counterparts to obtain preventive services (100). Data from NHANES show that women are more likely to have health insurance and see a healthcare provider (25). These low screening rates are especially concerning among 
young adults with multiple risk factors as the extent of atherosclerosis is directly correlated with the number of risk factors.

The AHA supports population-based strategies such as screenings at universities to identify at risk individuals $(16,97,101)$. Policy changes are needed to promote increased screening in primary care settings, clinics, schools, worksites and community sites. These screenings are particularly important in the young adult age group that may go otherwise undetected by the health care system (102) partly due to the underestimation of risk $(26,82,83)$. As discussed in the AHA's 2013 Science Advisory, screenings should include assessment of all CHD risk factors including lifestyle habits (diet, exercise and smoking), BP, glucose and BMI in addition to the traditional lipid panel (97). Screening, however, must be accompanied by reliable interpretation of results, provision of appropriate educational material and referral to a physician for those who need it, in order for follow-up to be most effective. Young adults should be informed of the meaning of their results, the importance of dietary changes and the appropriate follow-up steps that need to be taken depending on their other risk factors (102) (Figure 1). As outlined in the 2013 AHA/ACC Guidelines on Lifestyle Management to Reduce Cardiovascular Risk and in the 2013 ACC/AHA Guidelines on Assessment of Cardiovascular Risk, heart healthy nutrition and physical activity behaviors are recommended for all adults over age 18 for both prevention and treatment $(23,103)$. These preventive efforts are essential for reducing CHD events later in life and reducing the burden of CHD on a population level (97). Future research is needed to better understand and eliminate barriers to screening. This needs 
to be done at the policy, provider and patient level to improve suboptimal screening in young adults (104).

\section{Population-Based Nutrition Interventions in College Students}

Until primordial prevention strategies are successful in avoiding risk factor development all together, risk factor screening needs to work in tandem with education and management for effective disease prevention. Strategies that focus on high-risk individuals are effective in reducing CHD events but population-level strategies are needed to produce wide scale risk reductions $(16,97)$. Population-based interventions on college campuses are cost-effective strategies to manage existing risk factors by promoting lifestyle changes, which are the foundation for risk reduction efforts (103). The college setting is an ideal forum to reach large numbers of the young adult population as 12.5 million (nearly $50 \%$ ) of those ages $18-24$ years were enrolled in U.S. colleges and universities in 2010 (105). Interventions aimed at the college population represent an opportunity to promote healthy eating while lifestyle

habits are still being formed and to target CHD risk factors before disease progression occurs.

Previous population-based strategies have proven to be successful in reducing CHD risk in other populations (16). In the late 1980's, a population-based approach was used to lower CHD risk in the island nation of Mauritius. The fatty acid composition of imported cooking oil was changed to contain higher levels of polyunsaturated fat instead of saturated fat. The mean TC concentration fell from 225 $\mathrm{mg} / \mathrm{dL}$ in 1987 to $182 \mathrm{mg} / \mathrm{dL}$ in 1992, decreasing the prevalence of hypercholesterolemia from $25 \%$ to $6 \%$ in men and from $22 \%$ to $5 \%$ in women (106, 
107). This intervention was a classic example of a population-based strategy that effectively shifted the entire distribution of risk. Estimates from the World Heart Federation show that a universal reduction in sodium intake by 1 gram/day would lead to a $50 \%$ reduction in the number of individuals needing treatment for hypertension, a $22 \%$ decrease in deaths from stroke and a 16\% drop in deaths from CHD (28).

Similar population-based strategies can be applied to the college setting. Although cafeterias can contribute to an obesogenic environment on college campuses, they also represent an opportunity to influence students' diets for the better by providing nutrition information to guide healthy choices (108). To motivate students to choose healthier options, colleges need to identify healthy choices, provide nutrition information and utilize point-of-selection signage (77). This nutrition information may provide the stimulus for students to reevaluate and change their eating habits (109). Pyramids that displayed energy and nutrient content of menu offerings at a university cafeteria led $71 \%$ of patrons to change their lunch selections by choosing meals lower in energy and fat (110).

Peterson et al. (111) reported increased awareness of healthy foods as the primary reason for selecting healthier food choices in a dining hall intervention consisting of signs, table tents, flyers and benefit-based messages. Similar studies have also found that point-of-selection nutrition labels in dining halls resulted in better food choices and decreased energy intake at meals $(112,113)$. In another study, students with the highest nutrition knowledge were 12 times more likely to meet dietary recommendations compared to those with the lowest knowledge (114). Drawing attention to nutrition and health in a campus dining hall setting has a positive impact 
on food choices (111). Relatively small changes in the physical environment can produce behavioral changes (115). For example, placing healthy foods in more prominent places and removing trays from dining halls are other inexpensive ways to prompt healthier dietary choices.

Recently, technology has been used to promote behavior change. Technologybased interventions are particularly appealing to the young adult population and are quick, cost-effective and convenient ways to transmit information to a large audience (116). For example, messages displayed on computer screens at "point of decision" spots in a college dining hall influenced students to increase their fruit intake (117). Poddar et al. (118) demonstrated that 8 weeks of email messages as part of a dairy intake intervention were effective in increasing dairy intake in college students relative to the comparison group. Greene et al. (31) found that a 10-lesson, web-based nutrition and physical activity intervention resulted in higher fruit and vegetable intake and greater physical activity in 1689 college students from eight universities.

Other studies have also reported success with mobile technology-based interventions. (119-123). Text messaging, in particular, has been used in a variety of behavioral intervention studies to provide reminders, cues, positive reinforcement and enhance self-monitoring (124-127). All of these features are recognized as keys to successful maintenance of dietary changes (123). Text messaging is an especially appealing intervention mode for college students as $99.8 \%$ of college students own a cell phone and $97 \%$ of college students rely on text messaging as their main form of communication (128). 


\section{Conclusions:}

This review highlights the need for improved risk assessment and increased awareness in young adults. Cross-sectional studies provide evidence of the high prevalence of CHD risk factors in this age group. It is well established that these risk factors are associated with pathological changes and substantially increase lifetime CHD risk. Until successful primordial prevention strategies are part of the public health care infrastructure and prevent risk factors, the focus must be on improving screening, assessment, education and treatment of CHD risk factors. Targeting young adults at a time in their lives when lifelong habits are being developed is critical to prevent disease progression.

The low screening rates in this age group are concerning in light of the high prevalence of risk factors. Increased screening is the first step as young adults at risk must first be identified before treatment approaches can be initiated. College campuses provide an opportunity for population-based screening approaches. College students and health professionals on campus must first be made aware of the need for risk assessment and then risk reduction through lifestyle changes.

Future research needs to be done to identify the most effective and efficient ways of screening large numbers of young adults. Screenings embedded into course curricula in health courses, as part of university wellness programs or as a part of freshmen orientation are potential avenues to increase screening rates in this age group. Increased screening needs to work in conjunction with education to effectively identify and manage CHD risk. 


\section{Acknowledgments:}

All authors have read and approved the final manuscript. 


\section{References:}

1. Burke JD, Reilly RA, Morrell JS, Lofgren IE. The University of New Hampshire's Young Adult Health Risk Screening Initiative. J Am Diet Assoc. 2009; 109(10): 1751-8.

2. Fernandes J,Lofgren IE. Prevalence of metabolic syndrome and individual criteria in college students. J Am Coll Health. 2011; 59(4): 313-21.

3. Morrell JS, Lofgren IE, Burke JD, Reilly RA. Metabolic syndrome, obesity, and related risk factors among college men and women. J Am Coll Health. 2012; 60(1): 82-9.

4. Huang TT, Shimel A, Lee RE, Delancey W, Strother ML. Metabolic Risks among College Students: Prevalence and Gender Differences. Metab Syndr Relat Disord. 2007; 5(4): 365-72.

5. Strong JP, Malcom GT, McMahan CA, Tracy RE, Newman WP, 3rd, Herderick EE, Cornhill JF. Prevalence and extent of atherosclerosis in adolescents and young adults: implications for prevention from the Pathobiological Determinants of Atherosclerosis in Youth Study. JAMA. 1999; 281(8): 727-35.

6. Berenson GS, Srinivasan SR, Bao W, Newman WP, 3rd, Tracy RE, Wattigney WA. Association between multiple cardiovascular risk factors and atherosclerosis in children and young adults. The Bogalusa Heart Study. N Engl J Med. 1998; 338(23): 1650-6.

7. Ogden CL, Carroll MD, Kit BK, Flegal KM. Prevalence of obesity and trends in body mass index among US children and adolescents, 1999-2010. JAMA. 2012; 307(5): 483-90.

8. Juhola J, Magnussen CG, Viikari JS, Kahonen M, Hutri-Kahonen N, Jula A, Lehtimaki T, Akerblom HK, Pietikainen M, Laitinen T, et al. Tracking of serum lipid levels, blood pressure, and body mass index from childhood to adulthood: the Cardiovascular Risk in Young Finns Study. J Pediatr. 2011; 159(4): 584-90.

9. Reis JP, Loria CM, Lewis CE, Powell-Wiley TM, Wei GS, Carr JJ, Terry JG, Liu K. Association Between Duration of Overall and Abdominal Obesity Beginning in Young Adulthood and Coronary Artery Calcification in Middle Age. JAMA. 2013; 310(3): 280-288.

10. Boreham C, Twisk J, Murray L, Savage M, Strain JJ, Cran G. Fitness, fatness, and coronary heart disease risk in adolescents: the Northern Ireland Young Hearts Project. Med Sci Sports Exerc. 2001; 33(2): 270-4.

11. Sacheck JM, Kuder JF, Economos CD. Physical fitness, adiposity, and metabolic risk factors in young college students. Med Sci Sports Exerc. 2010; 42(6): 1039-44.

12. Narayan KM, Boyle JP, Thompson TJ, Gregg EW, Williamson DF. Effect of BMI on lifetime risk for diabetes in the U.S. Diabetes Care. 2007; 30(6): 15626.

13. Centers for Disease Control and Prevention. Health, United States, 2010. 2010

14. Heidenreich PA, Trogdon JG, Khavjou OA, Butler J, Dracup K, Ezekowitz MD, Finkelstein EA, Hong Y, Johnston SC, Khera A, et al. Forecasting the 
future of cardiovascular disease in the United States: a policy statement from the American Heart Association. Circulation. 2011; 123(8): 933-44.

15. Go AS, Mozaffarian D, Roger VL, Benjamin EJ, Berry JD, Borden WB, Bravata DM, Dai S, Ford ES, Fox CS, et al. Heart disease and stroke statistics-2013 update: a report from the American Heart Association. Circulation. 2013; 127(1): e6-e245.

16. Lloyd-Jones DM, Hong Y, Labarthe D, Mozaffarian D, Appel LJ, Van Horn L, Greenlund K, Daniels S, Nichol G, Tomaselli GF, et al. Defining and setting national goals for cardiovascular health promotion and disease reduction: the American Heart Association's strategic Impact Goal through 2020 and beyond. Circulation. 2010; 121(4): 586-613.

17. Third Report of the National Cholesterol Education Program (NCEP) Expert Panel on Detection, Evaluation, and Treatment of High Blood Cholesterol in Adults (Adult Treatment Panel III) final report. Circulation. 2002; 106(25): 3143-421.

18. National Heart, Lung and Blood Institute. The Seventh Report of the Joint National Committee on Prevention, Detection, Evaluation, and Treatment of High Blood Pressure. National Institutes of Health. p. 1-104.

19. Centers for Disease Control and Prevention. Health, United States, 2008 with Special Feature on the Health of Young Adults.

20. Camhi SM,Katzmarzyk PT. Tracking of cardiometabolic risk factor clustering from childhood to adulthood. Int J Pediatr Obes. 2010; 5(2): 122-9.

21. National Heart, Lung and Blood Institute. Expert Panel on Integrated Guidelines for Cardiovascular Health and Risk Reduction in Children and Adolescents, 2012.

22. Strasser T. Reflections on Cardiovascular-Diseases. Interdisciplinary Science Reviews. 1978; 3(3): 225-230.

23. Goff DC, Jr., Lloyd-Jones DM, Bennett G, Coady S, D'Agostino RB, Sr., Gibbons R, Greenland P, Lackland DT, Levy D, O'Donnell CJ, et al. 2013 ACC/AHA Guideline on the Assessment of Cardiovascular Risk: A Report of the American College of Cardiology/American Heart Association Task Force on Practice Guidelines. Circulation. 2013.

24. Executive Summary of The Third Report of The National Cholesterol Education Program (NCEP) Expert Panel on Detection, Evaluation, And Treatment of High Blood Cholesterol In Adults (Adult Treatment Panel III). JAMA. 2001; 285(19): 2486-97.

25. Kuklina EV, Yoon PW, Keenan NL. Prevalence of coronary heart disease risk factors and screening for high cholesterol levels among young adults, United States, 1999-2006. Ann Fam Med. 2010; 8(4): 327-33.

26. Munoz LR, Etnyre A, Adams M, Herbers S, Witte A, Horlen C, Baynton S, Estrada R, Jones ME. Awareness of Heart Disease Among Female College Students. Journal of Womens Health. 2010; 19(12): 2253-2259.

27. Stampfer MJ, Hu FB, Manson JE, Rimm EB, Willett WC. Primary prevention of coronary heart disease in women through diet and lifestyle. N Engl J Med. 2000; 343(1): 16-22. 
28. World Heart Federation. Diet and cardiovascular disease, 2013. Available from: http://www.world-heart-federation.org/cardiovascularhealth/cardiovascular-disease-risk-factors/diet/. Accessed June 22, 2013.

29. Hirshberg S, Fernandes, J, Melanson, K, Dwiggins, J, Lofgren, I. Dietary Sugars Predict Chronic Disease Risk Factors in College Students. Top Clin Nutr. 2011; 26: 324-334.

30. Irazusta A, Hoyos I, Irazusta J, Ruiz F, Diaz E, Gil J. Increased cardiovascular risk associated with poor nutritional habits in first-year university students. Nutrition Research. 2007; 27(7): 387-394.

31. Greene GW, White AA, Hoerr SL, Lohse B, Schembre SM, Riebe D, Patterson J, Kattelmann KK, Shoff S, Horacek T, et al. Impact of an Online Healthful Eating and Physical Activity Program for College Students. Am J Health Promot. 2012; 27(2): e47-58.

32. Rose N, Hosig K, Davy B, Serrano E, Davis L. Whole-grain intake is associated with body mass index in college students. J Nutr Educ Behav. 2007; 39(2): 90-4.

33. Ha EJ,Caine-Bish N. Interactive introductory nutrition course focusing on disease prevention increased whole-grain consumption by college students. $\mathbf{J}$ Nutr Educ Behav. 2011; 43(4): 263-7.

34. Johnson RK, Appel LJ, Brands M, Howard BV, Lefevre M, Lustig RH, Sacks F, Steffen LM, Wylie-Rosett J. Dietary sugars intake and cardiovascular health: a scientific statement from the American Heart Association. Circulation. 2009; 120(11): 1011-20.

35. Wells HF BJ, Dietary Assessment of major trends in US food consumption, 1970-2005. United States Department of Agriculture. Economic Research Service, Editor 2008.

36. Anderson JW, Hanna TJ, Peng X, Kryscio RJ. Whole grain foods and heart disease risk. J Am Coll Nutr. 2000; 19(3 Suppl): 291S-299S.

37. Grundy SM,Denke MA. Dietary influences on serum lipids and lipoproteins. J Lipid Res. 1990; 31(7): 1149-72.

38. Anderson JW,Hanna TJ. Whole grains and protection against coronary heart disease: what are the active components and mechanisms? Am J Clin Nutr. 1999; 70(3): 307-8.

39. Fernandez ML,West KL. Mechanisms by which dietary fatty acids modulate plasma lipids. J Nutr. 2005; 135(9): 2075-8.

40. Magnussen CG, Niinikoski H, Juonala M, Kivimaki M, Ronnemaa T, Viikari JS, Simell O, Raitakari OT. When and how to start prevention of atherosclerosis? Lessons from the Cardiovascular Risk in the Young Finns Study and the Special Turku Coronary Risk Factor Intervention Project. Pediatr Nephrol. 2011.

41. Rubin JB,Borden WB. Coronary heart disease in young adults. Curr Atheroscler Rep. 2012; 14(2): 140-9.

42. Holman RL, Mc GH, Jr., Strong JP, Geer JC. The natural history of atherosclerosis: the early aortic lesions as seen in New Orleans in the middle of the of the 20th century. Am J Pathol. 1958; 34(2): 209-35. 
43. Strong JP,McGill HC J. The natural history of coronary atherosclerosis. Am J Pathol. 1962; 40: 37-49.

44. Strong JP,McGill HC, Jr. The pediatric aspects of atherosclerosis. J Atheroscler Res. 1969; 9(3): 251-65.

45. Raitakari OT, Juonala M, Ronnemaa T, Keltikangas-Jarvinen L, Rasanen L, Pietikainen M, Hutri-Kahonen N, Taittonen L, Jokinen E, Marniemi J, et al. Cohort profile: the cardiovascular risk in Young Finns Study. Int J Epidemiol. 2008; 37(6): 1220-6.

46. Gall SL JK, Smith K, Dwyer T, Venn A. The childhood determinants of adult health study: a profile of a cohort study to examine the childhood influences on adult cardiovascular health. Austral Epidemiol. 2009; 16: 35-39.

47. Lauer RM, Connor WE, Leaverton PE, Reiter MA, Clarke WR. Coronary heart disease risk factors in school children: the Muscatine study. J Pediatr. 1975; 86(5): 697-706.

48. Dwyer T, Sun C, Magnussen CG, Raitakari OT, Schork NJ, Venn A, Burns TL, Juonala M, Steinberger J, Sinaiko AR, et al. Cohort Profile: the international childhood cardiovascular cohort (i3C) consortium. Int J Epidemiol. 2013; 42(1): 86-96.

49. Frerichs RR, Srinivasan SR, Webber LS, Berenson GR. Serum cholesterol and triglyceride levels in 3,446 children from a biracial community: the Bogalusa Heart Study. Circulation. 1976; 54(2): 302-9.

50. Mikkila V, Rasanen L, Raitakari OT, Pietinen P, Viikari J. Consistent dietary patterns identified from childhood to adulthood: the cardiovascular risk in Young Finns Study. Br J Nutr. 2005; 93(6): 923-31.

51. Gall SL, Jamrozik K, Blizzard L, Dwyer T, Venn A. Healthy lifestyles and cardiovascular risk profiles in young Australian adults: the Childhood Determinants of Adult Health Study. Eur J Cardiovasc Prev Rehabil. 2009; 16(6): 684-9.

52. Zieske AW, Malcom GT, Strong JP. Natural history and risk factors of atherosclerosis in children and youth: the PDAY study. Pediatr Pathol Mol Med. 2002; 21(2): 213-37.

53. Stary HC. Evolution and progression of atherosclerotic lesions in coronary arteries of children and young adults. Arteriosclerosis. 1989; 9(1 Suppl): I1932.

54. Juonala M, Jarvisalo MJ, Maki-Torkko N, Kahonen M, Viikari JS, Raitakari OT. Risk factors identified in childhood and decreased carotid artery elasticity in adulthood: the Cardiovascular Risk in Young Finns Study. Circulation. 2005; 112(10): 1486-93.

55. Raitakari OT, Juonala M, Kahonen M, Taittonen L, Laitinen T, Maki-Torkko $\mathrm{N}$, Jarvisalo MJ, Uhari M, Jokinen E, Ronnemaa T, et al. Cardiovascular risk factors in childhood and carotid artery intima-media thickness in adulthood: the Cardiovascular Risk in Young Finns Study. JAMA. 2003; 290(17): 227783.

56. McCrindle BW. Hyperlipidemia in children. Thromb Res. 2006; 118(1): 49-58. 
57. Cohn JN, Quyyumi AA, Hollenberg NK, Jamerson KA. Surrogate markers for cardiovascular disease: functional markers. Circulation. 2004; 109(25 Suppl 1): IV31-46.

58. Mancini GB, Dahlof B, Diez J. Surrogate markers for cardiovascular disease: structural markers. Circulation. 2004; 109(25 Suppl 1): IV22-30.

59. Juhola J, Magnussen CG, Berenson GS, Venn A, Burns TL, Sabin MA, Srinivasan SR, Daniels SR, Davis PH, Chen W, et al. Combined Effects of Child and Adult Elevated Blood pressure on Subclinical Atherosclerosis: The International Childhood Cardiovascular Cohort Consortium. Circulation. 2013.

60. Juonala M, Magnussen CG, Venn A, Dwyer T, Burns TL, Davis PH, Chen W, Srinivasan SR, Daniels SR, Kahonen M, et al. Influence of age on associations between childhood risk factors and carotid intima-media thickness in adulthood: the Cardiovascular Risk in Young Finns Study, the Childhood Determinants of Adult Health Study, the Bogalusa Heart Study, and the Muscatine Study for the International Childhood Cardiovascular Cohort (i3C) Consortium. Circulation. 2010; 122(24): 2514-20.

61. Oikonen M, Laitinen TT, Magnussen CG, Steinberger J, Sinaiko AR, Dwyer T, Venn A, Smith KJ, Hutri-Kahonen N, Pahkala K, et al. Ideal Cardiovascular Health in Young Adult Populations From the United States, Finland, and Australia and Its Association With cIMT: The International Childhood Cardiovascular Cohort Consortium. J Am Heart Assoc. 2013; 2(3): e000244.

62. Welsh JA, Sharma A, Cunningham SA, Vos MB. Consumption of added sugars and indicators of cardiovascular disease risk among US adolescents. Circulation. 2011; 123(3): 249-57.

63. Hu FB, Manson JE, Willett WC. Types of dietary fat and risk of coronary heart disease: a critical review. J Am Coll Nutr. 2001; 20(1): 5-19.

64. Shay CM, Ning H, Daniels SR, Rooks CR, Gidding SS, Lloyd-Jones DM. Status of Cardiovascular Health in US Adolescents: Prevalence Estimates From the National Health and Nutrition Examination Surveys (NHANES) 2005-2010. Circulation. 2013; 127(13): 1369-76.

65. Slining MM,Popkin BM. Trends in intakes and sources of solid fats and added sugars among U.S. children and adolescents: 1994-2010. Pediatr Obes. 2013.

66. May AL, Kuklina EV, Yoon PW. Prevalence of cardiovascular disease risk factors among US adolescents, 1999-2008. Pediatrics. 2012; 129(6): 1035-41.

67. Nelson MC, Story M, Larson NI, Neumark-Sztainer D, Lytle LA. Emerging adulthood and college-aged youth: an overlooked age for weight-related behavior change. Obesity 2008; 16(10): 2205-11.

68. Gordon-Larsen P, Adair LS, Nelson MC, Popkin BM. Five-year obesity incidence in the transition period between adolescence and adulthood: the National Longitudinal Study of Adolescent Health. Am J Clin Nutr. 2004; 80(3): 569-75.

69. Gordon-Larsen P, The NS, Adair LS. Longitudinal trends in obesity in the United States from adolescence to the third decade of life. Obesity (Silver Spring). 2010; 18(9): 1801-4. 
70. McDade TW, Chyu L, Duncan GJ, Hoyt LT, Doane LD, Adam EK. Adolescents' expectations for the future predict health behaviors in early adulthood. Soc Sci Med. 2011; 73(3): 391-8.

71. Levitsky DA, Halbmaier CA, Mrdjenovic G. The freshman weight gain: a model for the study of the epidemic of obesity. Int J Obes Relat Metab Disord. 2004; 28(11): 1435-42.

72. Hendricks KM,Herbold NH. Diet, activity, and other health-related behaviors in college-age women. Nutr Rev. 1998; 56(3): 65-75.

73. Ha EJ, Caine-Bish N, Holloman C, Lowry-Gordon K. Evaluation of effectiveness of class-based nutrition intervention on changes in soft drink and milk consumption among young adults. Nutr J. 2009; 8: 50.

74. Nishida C, Uauy R, Kumanyika S, Shetty P. The joint WHO/FAO expert consultation on diet, nutrition and the prevention of chronic diseases: process, product and policy implications. Public Health Nutr. 2004; 7(1A): 245-50.

75. Kobayashi T, Umemura U, Iso H, Ishimori M, Tamura Y, Iida M, Shimamoto T. Differences in dietary habits, serum fatty acid compositions and other coronary risk characteristics between freshmen and fourth-year male university students. Environ Health Prev Med. 2001; 6(3): 143-8.

76. Horacek TM, Erdman MB, Reznar MM, Olfert M, Brown-Esters ON, Kattelmann KK, Kidd T, Koenings M, Phillips B, Quick V, et al. Evaluation of the food store environment on and near the campus of 15 postsecondary institutions. Am J Health Promot. 2013; 27(4): e81-90.

77. Horacek TM, Erdman MB, Byrd-Bredbenner C, Carey G, Colby SM, Greene GW, Guo W, Kattelmann KK, Olfert M, Walsh J, et al. Assessment of the dining environment on and near the campuses of fifteen post-secondary institutions. Public Health Nutr. 2012: 1-11.

78. Byrd-Bredbenner C, Johnson M, Quick VM, Walsh J, Greene GW, Hoerr S, Colby SM, Kattelmann KK, Phillips BW, Kidd T, et al. Sweet and salty. An assessment of the snacks and beverages sold in vending machines on US postsecondary institution campuses. Appetite. 2012; 58(3): 1143-51.

79. Levitsky DA, Youn T. The more food young adults are served, the more they overeat. J Nutr. 2004; 134(10): 2546-9.

80. Holm-Denoma JM, Joiner TE, Vohs KD, Heatherton TF. The "freshman fifteen" (the "freshman five" actually): predictors and possible explanations. Health Psychol. 2008; 27(1 Suppl): S3-9.

81. Huang TT, Kempf AM, Strother ML, Li C, Lee RE, Harris KJ, Kaur H. Overweight and components of the metabolic syndrome in college students. Diabetes Care. 2004; 27(12): 3000-1.

82. Collins KA, Dantico M, Shearer NBC, Mossman KL. Heart disease awareness among college students. Journal of Community Health. 2004; 29(5): 405-420.

83. Cleeman JI,Grundy SM. National Cholesterol Education Program recommendations for cholesterol testing in young adults. A science-based approach. Circulation. 1997; 95(6): 1646-50.

84. Saenger AK. Universal lipid screening in children and adolescents: a baby step toward primordial prevention? Clin Chem. 2012; 58(8): 1179-81. 
85. Peterson AL,McBride PE. A review of guidelines for dyslipidemia in children and adolescents. WMJ. 2012; 111(6): 274-81; quiz 282.

86. Garber AM,Browner WS. Cholesterol screening guidelines. Consensus, evidence, and common sense. Circulation. 1997; 95(6): 1642-5.

87. U.S. Preventive Services Task Force. Screening for Lipid Disorders in Adults: Recommendation Statement. Am Fam Physician. 2009; 80(11): 1273-1274.

88. National Cholesterol Education Program (NCEP): highlights of the report of the Expert Panel on Blood Cholesterol Levels in Children and Adolescents. Pediatrics. 1992; 89(3): 495-501.

89. Kavey RE, Allada V, Daniels SR, Hayman LL, McCrindle BW, Newburger JW, Parekh RS, Steinberger J. Cardiovascular risk reduction in high-risk pediatric patients: a scientific statement from the American Heart Association Expert Panel on Population and Prevention Science; the Councils on Cardiovascular Disease in the Young, Epidemiology and Prevention, Nutrition, Physical Activity and Metabolism, High Blood Pressure Research, Cardiovascular Nursing, and the Kidney in Heart Disease; and the Interdisciplinary Working Group on Quality of Care and Outcomes Research: endorsed by the American Academy of Pediatrics. Circulation. 2006; 114(24): 2710-38.

90. United States Preventive Services Task Force. U.S. Preventive Services Task Force.Screening for Lipid Disorders in Children: Recommendation Statement. 2007; Available from:

http://www.uspreventiveservicestaskforce.org/uspstf07/chlipid/chlipidrs.htm. Accessed June 12, 2013.

91. Daniels SR,Greer FR. Lipid screening and cardiovascular health in childhood. Pediatrics. 2008; 122(1): 198-208.

92. Familial Hypercholesterolemia: Screening, Diagnosis and Management of Pediatric and Adult Patients Clinical Guidance from the National Lipid Association Expert Panel on Familial Hypercholesterolemia. Journal of Clinical Lipidology. 2011; 5(35): S 1-58.

93. Expert panel on integrated guidelines for cardiovascular health and risk reduction in children and adolescents: summary report. Pediatrics. 2011; 128 Suppl 5: S213-56.

94. Gillman MW,Daniels SR. Is Universal Pediatric Lipid Screening Justified? Jama-Journal of the American Medical Association. 2012; 307(3): 259-260.

95. Psaty BM,Rivara FP. Universal Screening and Drug Treatment of Dyslipidemia in Children and Adolescents. Jama-Journal of the American Medical Association. 2012; 307(3): 257-258.

96. Newman TB, Pletcher MJ, Hulley SB. Overly Aggressive New Guidelines for Lipid Screening in Children: Evidence of a Broken Process. Pediatrics. 2012; 130(2): 349-352.

97. Spring B, Ockene JK, Gidding SS, Mozaffarian D, Moore S, Rosal MC, Brown MD, Vafiadis DK, Cohen DL, Burke LE, et al. Better population health through behavior change in adults: a call to action. Circulation. 2013; 128(19): 2169-76. 
98. Laitinen TT, Pahkala K, Magnussen CG, Viikari JS, Oikonen M, Taittonen L, Mikkila V, Jokinen E, Hutri-Kahonen N, Laitinen T, et al. Ideal cardiovascular health in childhood and cardiometabolic outcomes in adulthood: the Cardiovascular Risk in Young Finns Study. Circulation. 2012; 125(16): 19718.

99. Disparities in screening for and awareness of high blood cholesterol--United States, 1999-2002. MMWR Morb Mortal Wkly Rep. 2005; 54(5): 117-9.

100. United States Department of Health and Human Services. Utilization of Ambulatory Medical Care by Women: United States, 1997-98. 2001; Available from: http://www.cdc.gov/nchs/data/series/sr_13/sr13_149.pdf. Accessed September 20, 2013.

101. American Heart Association Scientific Position: Public Cholesterol Screening (Adults and Children). 2012; Available from:

http://www.heart.org/HEARTORG/Conditions/Cholesterol/SymptomsDiagnos isMonitoringofHighCholesterol/Public-Cholesterol-Screening-Adults-andChildren_UCM_305617_Article.jsp. Accesed July 9, 2013.

102. Carleton RA, Dwyer J, Finberg L, Flora J, Goodman DS, Grundy SM, Havas S, Hunter GT, Kritchevsky D, Lauer RM. Report of the Expert Panel on Population Strategies for Blood Cholesterol Reduction. A statement from the National Cholesterol Education Program, National Heart, Lung, and Blood Institute, National Institutes of Health. Circulation. 1991; 83(6): 2154-2232.

103. Eckel RH, Jakicic JM, Ard JD, Hubbard VS, de Jesus JM, Lee IM, Lichtenstein AH, Loria CM, Millen BE, Miller NH, et al. 2013 AHA/ACC Guideline on Lifestyle Management to Reduce Cardiovascular Risk: A Report of the American College of Cardiology/American Heart Association Task Force on Practice Guidelines. Circulation. 2013.

104. Robbins CL, Dietz PM, Bombard JM, Gibbs F, Ko JY, Valderrama AL. Blood pressure and cholesterol screening prevalence among U.S. women of reproductive age opportunities to improve screening. Am J Prev Med. 2011; 41(6): 588-95.

105. United States Department of Education. National Center for Education Statistics. Digest of Education Statistics, 2011. 2012.

106. Dowse GK, Gareeboo H, Alberti KG, Zimmet P, Tuomilehto J, Purran A, Fareed D, Chitson P, Collins VR. Changes in population cholesterol concentrations and other cardiovascular risk factor levels after five years of the non-communicable disease intervention programme in Mauritius. Mauritius Non-communicable Disease Study Group. BMJ. 1995; 311(7015): 1255-9.

107. Uusitalo U, Feskens EJ, Tuomilehto J, Dowse G, Haw U, Fareed D, Hemraj F, Gareeboo H, Alberti KG, Zimmet P. Fall in total cholesterol concentration over five years in association with changes in fatty acid composition of cooking oil in Mauritius: cross sectional survey. BMJ. 1996; 313(7064): 10446.

108. Gorman N, Lackney JA, Rollings K, Huang TT. Designer schools: the role of school space and architecture in obesity prevention. Obesity (Silver Spring). 2007; 15(11): 2521-30. 
109. Conklin MT, Cranage, David A., Lambert, Carolyn U. . College students' use of point of selection nutrition information. Topics in Clinical Nutrition. 2005; 20(2): 97-108.

110. Turconi G, Bazzano R, Roggi C, Cena H. Helping consumers make a more conscious nutritional choice: acceptability of nutrition information at a cafeteria. Public Health Nutr. 2012; 15(5): 792-801.

111. Peterson S, Duncan DP, Null DB, Roth SL, Gill L. Positive changes in perceptions and selections of healthful foods by college students after a shortterm point-of-selection intervention at a dining hall. J Am Coll Health. 2010; 58(5): 425-31.

112. Freedman MR,Connors R. Point-of-Purchase Nutrition Information Influences Food-Purchasing Behaviors of College Students: A Pilot Study (Reprinted from American Dietetic Association, vol 110, pg 1222-1226, 2010). Journal of the American Dietetic Association. 2011; 111(5): S42-S46.

113. Driskell JA, Schake MC, Detter HA. Using Nutrition Labeling as a Potential Tool for Changing Eating Habits of University Dining Hall Patrons. Journal of the American Dietetic Association. 2008; 108(12): 2071-2076.

114. Kresic G, Kendel Jovanovic G, Pavicic Zezel S, Cvijanovic O, Ivezic G. The effect of nutrition knowledge on dietary intake among Croatian university students. Coll Antropol. 2009; 33(4): 1047-56.

115. Kremers SPJ, Eves, F.F., Andersen, R.E. Environmental Changes to Promote Physical Activity and Healthy Dietary Behavior. Journal of Environmental and Public Health. 2012.

116. Sirriyeh R, Lawton R, Ward J. Physical activity and adolescents: an exploratory randomized controlled trial investigating the influence of affective and instrumental text messages. Br J Health Psychol. 2010; 15(Pt 4): 825-40.

117. Reed JA, Powers A, Greenwood M, Smith W, Underwood R. Using "point of decision" messages to intervene on college students' eating behaviors. Am J Health Promot. 2011; 25(5): 298-300.

118. Poddar KH, Hosig KW, Anderson-Bill ES, Nickols-Richardson SM, Duncan SE. Dairy intake and related self-regulation improved in college students using online nutrition education. J Acad Nutr Diet. 2012; 112(12): 1976-86.

119. Spring B, Duncan JM, Janke EA, Kozak AT, McFadden HG, Demott A, Pictor A, Epstein LH, Siddique J, Pellegrini CA, et al. Integrating Technology Into Standard Weight Loss Treatment: A Randomized Controlled Trial. Arch Intern Med. 2012: 1-7.

120. Spring B, Schneider K, McFadden HG, Vaughn J, Kozak AT, Smith M, Moller AC, Epstein LH, Demott A, Hedeker D, et al. Multiple behavior changes in diet and activity: a randomized controlled trial using mobile technology. Arch Intern Med. 2012; 172(10): 789-96.

121. Schembre SM,Yuen J. Project TwEATs. A feasibility study testing the use of automated text messaging to monitor appetite ratings in a free-living population. Appetite. 2011; 56(2): 465-8.

122. Kerr DA, Pollard CM, Howat P, Delp EJ, Pickering M, Kerr KR, Dhaliwal SS, Pratt IS, Wright J, Boushey CJ. Connecting Health and Technology (CHAT): protocol of a randomized controlled trial to improve nutrition behaviours using 
mobile devices and tailored text messaging in young adults. BMC Public Health. 2012; 12: 477.

123. Patrick K, Raab F, Adams MA, Dillon L, Zabinski M, Rock CL, Griswold WG, Norman GJ. A text message-based intervention for weight loss: randomized controlled trial. J Med Internet Res. 2009; 11(1): e1.

124. Armstrong AW, Watson AJ, Makredes M, Frangos JE, Kimball AB, Kvedar JC. Text-message reminders to improve sunscreen use: a randomized, controlled trial using electronic monitoring. Arch Dermatol. 2009; 145(11): 1230-6.

125. Hanauer DA, Wentzell K, Laffel N, Laffel LM. Computerized Automated Reminder Diabetes System (CARDS): e-mail and SMS cell phone text messaging reminders to support diabetes management. Diabetes Technol Ther. 2009; 11(2): 99-106.

126. Hou MY, Hurwitz S, Kavanagh E, Fortin J, Goldberg AB. Using daily textmessage reminders to improve adherence with oral contraceptives: a randomized controlled trial. Obstet Gynecol. 2010; 116(3): 633-40.

127. Prabhakaran L, Chee WY, Chua KC, Abisheganaden J, Wong WM. The use of text messaging to improve asthma control: a pilot study using the mobile phone short messaging service (SMS). J Telemed Telecare. 2010; 16(5): 28690.

128. Hanley M. Student Smartphone Use Doubles; Instant Messaging Loses Favor; Available from: http://chronicle.com/blogs/wiredcampus/student-smartphoneuse-doubles-instant-messaging-loses-favor/24876. Accessed October 10, 2012. 
Table 1: Cohort Studies

\begin{tabular}{|c|c|c|c|c|c|}
\hline Authors (ref.) & Study, Country & $\begin{array}{c}\text { Year } \\
\text { Baseline }\end{array}$ & Subjects & $\begin{array}{c}\text { Year } \\
\text { Follow-Up }\end{array}$ & Key Outcomes \\
\hline Lauer et al. (47) & Muscatine, USA & 1970 & $\begin{array}{c}\mathrm{n}=11,337 \\
5-18 \text { yo }\end{array}$ & $\begin{array}{c}1970-1981 \\
1982-1991 \\
\text { 1992-ongoing }\end{array}$ & $\begin{array}{l}\text { TC: } 37 \%>200 \mathrm{mg} / \mathrm{dL} \\
\text { TG: } 15 \%>140 \mathrm{mg} / \mathrm{dL} \\
\text { BP: } 21 \% \geq 140 / 90 \mathrm{mmHg} \\
\text { Weight: } 33 \% \geq 110 \% \text { relative weight } \\
\text { Elevated TC, TG, BP and relative weight in youth predict } \\
\text { CHD in adults }\end{array}$ \\
\hline Berenson et al. (6) & Bogalusa Heart, USA & 1973 & $\begin{array}{c}n=12,164 \\
4-17 \text { yo }\end{array}$ & $\begin{array}{c}\text { 1977-1996 } \\
2001-2002 \\
2003-2005 \\
\text { 2007-ongoing }\end{array}$ & $\begin{array}{l}\text { Pathological changes occur by } 5-8 \text { years of age } \\
\text { Extent of lesions significantly related to levels of TC, } \\
\text { LDL-C, TG, BMI, HDL-C and BP }\end{array}$ \\
\hline Raitakari et al. (45) & $\begin{array}{l}\text { Cardiovascular Risk in } \\
\text { Young Finns, Finland }\end{array}$ & 1980 & $\begin{array}{l}n=3,596 \\
3-18 \text { yo }\end{array}$ & 1983-ongoing & $\begin{array}{l}\text { CVD risk factors (elevated TC, LDL-C, BP, smoking) early } \\
\text { in life lead to structural and functional vascular changes } \\
\text { related to atherosclerosis } \\
\text { Increased LDL-C, BP, obesity and cigarette smoke } \\
\text { in adolescence predict increased cIMT and decreased } \\
\text { elasticity in adulthood }\end{array}$ \\
\hline Gall et al. (46) & $\begin{array}{l}\text { Childhood Determinants } \\
\text { of Adult Health Study, USA }\end{array}$ & 1985 & $\begin{array}{c}\mathrm{n}=8,498 \\
7-15 \text { yo }\end{array}$ & $\begin{array}{l}\text { 2004-2006 } \\
\text { 2013-ongoing }\end{array}$ & $\begin{array}{l}\text { Childhood physical activity, obesity and TC are important } \\
\text { determinants of adult CVD risk factors } \\
\text { (obesity, IR, dyslipidemia, cIMT) }\end{array}$ \\
\hline
\end{tabular}

$\mathrm{BP}$, blood pressure; CHD, coronary heart disease; cIMT, carotid intima media thickness; CVD, cardiovascular disease; HDL-C, HDL cholesterol; IR, insulin resistance; LDL-C, LDL cholesterol; TC, total cholesterol 
Table 2: CHD Risk Factor Prevalence in College Students

\begin{tabular}{|c|c|c|c|c|c|c|c|}
\hline Authors (ref.) & $\begin{array}{c}\text { TC } \\
(\geq 200 \mathrm{mg} / \mathrm{dL})\end{array}$ & $\underset{(\geq 100 \mathrm{mg} / \mathrm{dL})}{\mathrm{LDL}-\mathrm{C}}$ & $\begin{array}{c}\text { HDL-C } \\
(<40 \mathrm{M},<50 \mathrm{~F} \mathrm{mg} / \mathrm{dL})\end{array}$ & $\underset{(\geq 150 \mathrm{mg} / \mathrm{dL})}{\mathbf{T G}}$ & $\underset{(\geq 100 \mathbf{~ m g} / \mathbf{d L})}{\text { Glu }}$ & $\begin{array}{c}\text { BP } \\
(\geq 130 / 85 \mathrm{mmHg})\end{array}$ & $\begin{array}{c}\text { WC } \\
(>102 \mathrm{M},>88 \mathrm{~F} \mathrm{~cm})\end{array}$ \\
\hline \multicolumn{8}{|c|}{ Fernandes et al. (2) } \\
\hline M & -- & -- & 3.2 & 3.7 & 2.1 & 2.1 & 1.1 \\
\hline $\mathrm{F}$ & -- & -- & 16.9 & 13.8 & 5.3 & 0.0 & 6.3 \\
\hline \multicolumn{8}{|l|}{ Huang et al. (4) } \\
\hline M & -- & - & 22.5 & 15.7 & 14.7 & 13.7 & 2.9 \\
\hline $\mathrm{F}$ & -- & -- & 25.3 & 5.6 & 7.6 & 0.5 & 2.5 \\
\hline \multicolumn{8}{|l|}{ Burke et al. (1) } \\
\hline M & 27.0 & 63.0 & 29.0 & -- & 8.0 & -- & 4.0 \\
\hline $\mathrm{F}$ & 27.0 & 47.0 & 23.0 & -- & 5.0 & -- & 4.0 \\
\hline \multicolumn{8}{|l|}{ Morrell et al. (3) } \\
\hline M & 24.7 & 61.9 & 30.6 & 12.2 & 13.7 & 62.1 & 5.2 \\
\hline $\mathrm{F}$ & 25.8 & 45.5 & 23.7 & 18.3 & 6.4 & 21.2 & 4.2 \\
\hline
\end{tabular}

BP, blood pressure; Glu, glucose; HDL-C, HDL cholesterol; LDL-C, LDL cholesterol; TC, total cholesterol; WC, waist circumference 
Figure 1: Progression of Atherosclerosis and Prevention Targets

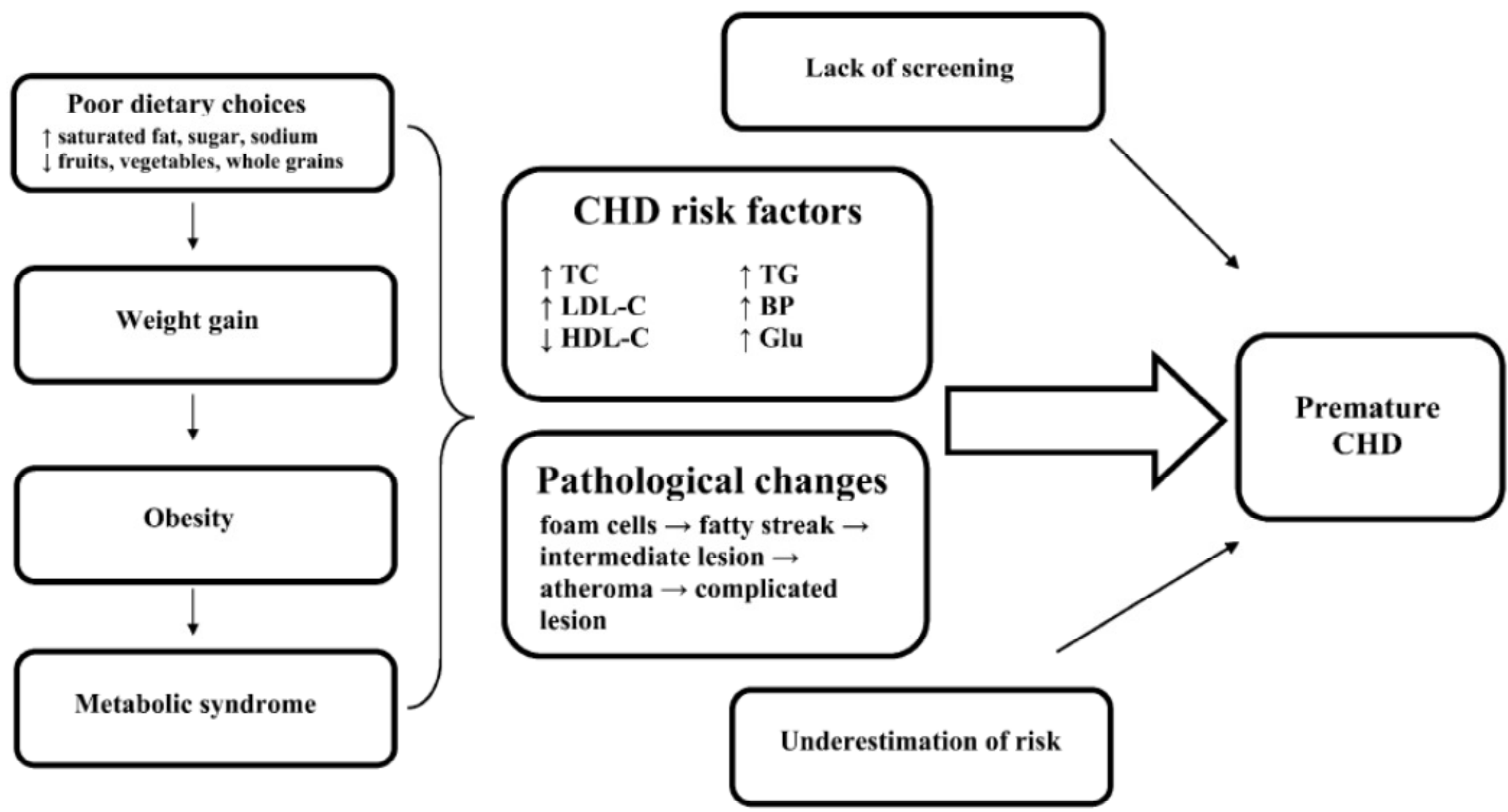

BP, blood pressure; CHD, coronary heart disease; Glu, glucose; HDL-C, HDL cholesterol; LDL-C, LDL cholesterol; TC, total cholesterol 


\section{MANUSCRIPT 2}

"A Population-Based Nutrition Intervention to Increase Whole Grain Intake in College Students" is prepared for submission to the American Journal of Health Promotion. 


\section{ABSTRACT:}

Purpose: The purpose of this study was to increase whole grain intake in college students through a population-based intervention in campus dining halls. The secondary aim was to improve coronary heart disease (CHD) risk factors. The exploratory aims were to evaluate the impact of a text messaging intervention on whole grain and low-fat dairy intake and CHD risk factors in a subsample of participants. Design: Quasi-experimental with measurements at baseline, postintervention, and follow-up (6 months). Subjects: College students (18-24 years old, n=98) from a northeastern U.S. university. Intervention: A 6-week population-based intervention consisting of benefit-based whole grain and low-fat dairy messages in campus dining halls. Daily text messages or emails were sent to the subsample $(n=26)$. Measures: Dietary intake, anthropometrics, blood lipids, fasting glucose and blood pressure were assessed at each time point. Analysis: Repeated measures analysis of variance. Results: Whole grain intake increased over time $(0.8 \pm 1.1 \mathrm{oz}$ to $1.1 \pm 1.5 \mathrm{oz}$, $\mathrm{p}=0.008$ ). High-density lipoprotein cholesterol (HDL-C), body weight and body mass index (BMI) significantly increased over time. Total dairy intake decreased over time. Conclusion: A 6-week population-based messaging intervention in campus dining halls had a positive impact on whole grain consumption and on HDL-C in college students. Future research should focus on population-based weight reduction interventions in this age group. Also, findings suggest that tailored interventions targeting dairy intake in this group are warranted. 


\section{INTRODUCTION:}

Heart disease is a leading cause of death in young adults ${ }^{1}$. Many coronary heart disease (CHD) risk factors surface in adolescence ${ }^{1-4}$ and track forward to adulthood ${ }^{5}$. Since $80 \%$ of cardiovascular events are preventable through diet and lifestyle ${ }^{6}$, primordial and primary prevention approaches are emphasized in the American Heart Association's 2020 Strategic Impact Goals ${ }^{7}$ and in the National Heart, Lung and Blood Institute's 2012 Expert Panel on Integrated Guidelines for

Cardiovascular Health and Risk Reduction in Children and Adolescents ${ }^{8}$. Despite this emphasis on the importance of early prevention efforts, little has been done to address CHD risk in young adults who are unaware ${ }^{9}$ and have not been screened for CHD risk 10

The few cross-sectional studies that have assessed CHD risk in college students ages 18-24 demonstrate the need for increased screening, risk assessment and disease prevention in this age group ${ }^{11-14}$. More than $50 \%$ of college students have elevated low-density lipoprotein cholesterol (LDL-C) ${ }^{15}$. Additionally, as many as $27 \%$ have elevated total cholesterol (TC), $47 \%$ have hypertension ${ }^{15}, 18 \%$ have elevated triacylglycerides (TAG), 20\% have low high-density lipoprotein cholesterol (HDL-C) ${ }^{14}$ and $13 \%$ have elevated glucose ${ }^{16}$. These risk factors are strongly correlated with the extent of atherosclerotic lesions ${ }^{17}$, which progress to advanced lesions in as many as $20 \%$ of young adults ${ }^{18}$.

Typical diets consumed by college students, which are high in saturated fat ${ }^{19}$ and low in whole grains ${ }^{20}$ negatively affect these risk factors, especially LDL-C. More than $70 \%$ of college students exceed total and saturated fat recommendations ${ }^{19}$. They also fail to meet whole grain recommendations ${ }^{20,21}$, consuming only $12 \%(0.37$ 
$\mathrm{oz}$ ) of the recommended minimum of $3 \mathrm{oz}{ }^{20}$. Low-density lipoprotein cholesterol concentrations can be improved by decreasing saturated fat and increasing whole grain consumption $^{22,23}$. Saturated fat reduces LDL receptor-mediated clearance by decreasing the number of LDL receptors via reduced transcription of the LDL receptor gene $^{24}$. Receptor activity is also reduced by saturated fat due to negative changes in membrane fluidity that interfere with LDL binding to the LDL receptor ${ }^{23,25,26}$. The LDL-C lowering effect observed with whole grain intake is associated with the soluble fiber component of the grain ${ }^{27}$. Soluble fiber binds bile acids in the small intestine and leads to their excretion, preventing their normal reabsorption and reutilization ${ }^{28}$, 29. This causes the liver to synthesize additional bile acids from cholesterol, which lowers the cholesterol content of hepatocytes, stimulating LDL receptor production and subsequent clearance of LDL-C from circulation ${ }^{28,29}$.

Because $42 \%$ of US young adults attend college or universities ${ }^{30}$, these campuses provide an ideal opportunity to target young adults at a point in life when lifestyle choices are being made and before disease progression occurs ${ }^{31}$. Previous research has demonstrated that increased awareness of healthy options through pointof-selection (POS) signage and benefit-based messages has increased the selection of healthier options in university dining halls ${ }^{32-34}$. Recently, technology has been used to promote behavior change in college students ${ }^{35-38}$ but no studies have utilized text messaging to produce dietary changes in this age group. To the best of our knowledge, this is the first study to utilize both point-of-selection and text messaging in a nutrition intervention on a college campus. The purpose of this study was to increase whole grain consumption through a population-based intervention in campus 
dining halls. A secondary aim was to improve CHD risk factors. An exploratory aim was to analyze the impact of a text messaging intervention on whole grain and low-fat dairy intake and CHD risk factors in a subsample of participants.

\section{METHODS:}

Design

A quasi-experimental design was used to assess the impact of a populationbased whole grain and low-fat dairy intervention on CHD risk factors. Baseline and post-intervention assessments were conducted immediately before and after the sixweek intervention and the follow-up assessment occurred six months after the baseline assessment. A subsample ( $\mathrm{n}=26$ ) was recruited for Heart Start II, which involved additional measures. All measurements described were obtained at baseline, postintervention and follow-up.

\section{Sample}

Participants were recruited via classroom announcements at a medium sized northeastern university. Eligible participants were 18-24 year old males and females with a campus meal plan and a BMI $\geq 18.5 \mathrm{~kg} / \mathrm{m}^{2}$. Exclusion criteria included being pregnant or lactating, or self-report of one of the following conditions: eating disorder, liver disease, bleeding disorder, diabetes, cancer, or CHD. All participants read and signed an informed consent approved by the University's Institutional Review Board. 
Measures

\section{Dietary Intake}

The National Health and Nutrition Examination Survey (NHANES) 2009-2010 National Cancer Institute Dietary Screener Questionnaire (NCI Screener) was used to assess intake of fruits and vegetables, dairy/calcium, whole grains/fiber, added sugars, red meat, and processed meat in all participants ${ }^{39}$.

Purchasing records from dining services were used as a proxy for whole grain and low-fat dairy consumption. Purchasing records were obtained for bread and dairy products that offered a whole grain or low-fat dairy alternative (bread, rolls, breadsticks, English muffins, milk and yogurt) to determine if students selected the whole grain or low-fat dairy option. Purchasing records were obtained at baseline, intervention, post-intervention and 6-month follow-up. Average values were calculated for individual items at each time point and were used for the analyses.

Twenty-four hour dietary recalls were collected and analyzed for Heart Start II participants $(n=26)$ using the multiple pass method in conjunction with the Nutrition Data System for Research (NDS-R) software (University of Minnesota, Minneapolis, MN) version 2012. All participants completed three 24-hour dietary recalls: one inperson and two over the phone on three non-consecutive days (including two weekdays and one weekend day) ${ }^{40,41}$. Nasco food models (eNasco, Fort Atkinson, WI) and food amounts booklets were available during the initial in-person 24-hour recall to more accurately estimate portion size ${ }^{42}$. Participants were given the booklets after the initial recall for the phone recalls. The mean values of the three recalls 
provided dietary data for analysis. Healthy Eating Index 2010 scores were calculated from the mean values from the three 24-hour recalls for Heart Start II participants to assess diet quality in Heart Start II participants $(n=26)$.

\section{Biochemical}

Following a 12-hour fast, finger sticks were performed on all participants to obtain blood samples for determination of blood lipid and glucose concentrations. Values for LDL-C, TC, TAG, HDL-C and glucose were obtained using Cholestech LDX table-top analyzers (Cholestech, Hayward, CA).

\section{Anthropometrics}

Height was measured to the nearest $0.1 \mathrm{~cm}$ using a Seca 220 stadiometer (Seca Corporation, Hamburg, Germany). Weight was measured to the nearest $0.1 \mathrm{~kg}$ using a calibrated digital Seca 769 scale (Seca Corporation, Hamburg, Germany).

Measurements were taken in duplicate and the average of the two values was used for the analysis. Body mass index was calculated using the following formula: weight in kilograms/height in meters ${ }^{2}$. Waist circumference was measured in duplicate at the top of the iliac crest upon exhalation to the nearest $0.1 \mathrm{~cm}$ using a Gulick fiberglass, non-stretchable tape measure with an attached tensometer (Patterson Medical, Mount Joy, PA). The average of the two values was used for the analysis.

\section{Blood Pressure}

Blood pressure was measured after a 5 minute seated rest period using an automatic blood pressure monitor with arm cuff (Omron HEI-711, Omron Health Care 
Products, Issaquah, WA). Measurements were re-taken two minutes apart until values were within $2 \mathrm{mmHg}$. The average of the two values in agreement was used for the analysis.

\section{Intervention}

Heart Start I and II participants were exposed to a 6-week intervention which consisted of benefit-based nutrition messages in the two main campus dining halls (Hope and Butterfield). Messages were displayed on television monitors and on pointof-selection signs at the deli and dairy stations in both dining halls. Prompts to choose whole grain bread were also verbally provided by the deli station staff in both dining halls. Additionally, nutrition education booths to promote whole grain and low-fat dairy consumption were positioned in a high traffic area outside of Hope. Message and booth content alternated between whole grains and low-fat dairy each week. Students with meal plans were able to eat at either dining hall and all students who ate at the dining halls were exposed to the intervention.

Intervention materials addressed specific motivators of healthy eating (increased energy, healthy body weight and staying full) from previously conducted

focus groups ${ }^{43}$. Additionally, Heart Start II participants received the same nutrition message that was displayed on the television monitors in the dining halls each weekday via text message or email, depending on their preference. Google Voice (Google, Mountain View, CA), a web-based application, was used to deliver text messages. 
Analysis

Descriptive statistics were performed and skewness and kurtosis were examined to determine data distribution. Non-normally distributed data were transformed. Body mass index, LDL-C, total grains, low-fat dairy and soluble fiber were log transformed. Triacylglycerides and sugar-sweetened beverages (SSB) were square root transformed. Whole grains, semi-whole grains, total fiber, reduced fat dairy, glucose and systolic blood pressure (SBP) were analyzed using non-parametric tests. Continuous variables were expressed as mean \pm standard deviation and categorical variables were expressed as frequencies. Repeated measures analysis of variance with post hoc tests using the Bonferroni adjustment were used to determine if there were significant differences over time. The Friedman test with post hoc Wilcoxon signed rank tests using a Bonferroni adjusted alpha value were used to assess differences over time for whole grains, semi-whole grains, fiber and glucose. Mixed between-within analysis of variance assessed differences between groups over time. Chi-square tests were used to analyze categorical variables. Statistical significance was set at $\mathrm{p}<0.05$ for all tests.

\section{RESULTS:}

Participant characteristics at baseline are presented in Table 1. The majority of the sample was female (78\%) and Caucasian (81\%). The mean age was $18.2 \pm 0.6$ years. At baseline, more than $50 \%$ of females and $36 \%$ of males had low HDL-C for gender ( $<40 \mathrm{M},<50 \mathrm{~F}$ mg/dL), 19\% had elevated LDL-C ( $\geq 100 \mathrm{mg} / \mathrm{dL}), 14 \%$ had elevated TAG $(\geq 150 \mathrm{mg} / \mathrm{dL})$ and $13 \%$ had elevated SBP $(\geq 130 \mathrm{mmHg})$. More than 
$80 \%$ of the sample had never or were unsure as to whether they ever had their cholesterol checked. Sixty-three Heart Start I participants completed all three assessment visits and 18 of these 63 completed additional measurements for Heart Start II.

Data from the NCI Screener indicated that whole grain intake increased over time $\left(\chi^{2}(2, \mathrm{n}=69)=10.6, \mathrm{p}=0.005\right)$. Whole grain intake increased from baseline to follow-up $(0.8 \pm 1.1 \mathrm{oz}$ to $1.1 \pm 1.5 \mathrm{oz}, \mathrm{p}=0.008)$ and from post-intervention to followup $(0.8 \pm 0.8 \mathrm{oz}$ to $1.1 \pm 1.5 \mathrm{oz}, \mathrm{p}=0.006)$. Purchasing record data (used as a proxy for consumption) indicated that percent whole grain consumption doubled (12.7\% to 23.9\%) in the dining hall with nutrition education booths, point-of-selection signs, promotion by deli counter staff and messaging on television monitors (Hope) during the 6 week intervention (data not shown). In Hope, baseline whole grain consumption was significantly lower than the intervention and follow-up period but not different from post-intervention. In Butterfield, whole grain consumption significantly increased across baseline, post-intervention and follow-up periods and was higher than consumption at Hope at all time points.

As displayed in Table 2, there were no changes in LDL-C over time (Wilks' Lambda $\left.=0.94, F_{2,56}=1.83, \mathrm{p}=0.17, \eta^{2}=0.06\right)$. However, positive changes were seen in HDL-C over time (Wilks' Lambda $=0.82, F_{2,59}=6.66, \mathrm{p}=0.002, \eta^{2}=0.18$ ). There was also a significant effect of time for glucose $\left(\chi^{2}(2, n=61)=11.92, p=0.003\right)$. Significant increases in body weight (Wilks' Lambda $=0.72, F_{2,61}=11.84, \mathrm{p}<0.001$, $\eta^{2}=0.28$ ) and BMI (Wilks' Lambda $=0.78, F_{2,61}=8.44, \mathrm{p}=0.001, \eta^{2}=0.22$ ) were observed over time. 
There was no primary measure of low-fat dairy intake. However, purchasing records used as a proxy for dairy intake indicated that nonfat dairy increased by $3-4 \%$ during the intervention and were significantly higher at follow-up compared to other time points in Hope (data not shown). Data from the NCI screener showed that total dairy intake decreased over time (Wilks' Lambda $=0.85, F_{2,69}=6.16, \mathrm{p}=0.003$, $\eta^{2}=0.15$ ). Sugar-sweetened beverages (SSB) also significantly decreased over time (Wilks' Lambda $=0.86, F_{2,70}=5.72, \mathrm{p}=0.005, \eta^{2}=0.14$ ).

Exploratory analyses on Heart Start II participants $(n=18)$ revealed no changes over time in whole grain intake as assessed by 24 -hr dietary recalls (Wilks' Lambda $=$ $\left.0.95, F_{2,16}=0.40, \mathrm{p}=0.678, \eta^{2}=0.05\right)$. There were no changes in LDL-C over time (Wilks' Lambda $=0.95, F_{2,16}=0.40, \mathrm{p}=0.678, \eta^{2}=0.05$ ). High-density lipoprotein cholesterol increased (Wilks' Lambda $=0.63, F_{2,16}=4.63, \mathrm{p}=0.026, \eta^{2}=0.37$ ).

Heart Start II participants also had significant increases in weight (Wilks' Lambda $=0.58, F_{2,16}=5.89, \mathrm{p}=0.012, \eta^{2}=0.42$ ), BMI (Wilks' Lambda $=0.67, F_{2,16}$ $=3.91, \mathrm{p}=0.042, \eta^{2}=0.33$ ) and WC (Wilks' Lambda $=0.60, F_{2,16}=5.39, \mathrm{p}=0.016$, $\left.\eta^{2}=0.40\right)$ over time. Weight increased from baseline to post-intervention $(69.1 \pm 13.3$ $\mathrm{kg}$ to $70.1 \pm 13.7 \mathrm{~kg}, \mathrm{p}=0.029)$ and from baseline to follow-up $(69.1 \pm 13.3 \mathrm{~kg}$ to 70.6 $\pm 13.8 \mathrm{~kg}, \mathrm{p}=0.030$ ). Body mass index increased from baseline to post-intervention $\left(25.1 \pm 4.9 \mathrm{~kg} / \mathrm{m}^{2}\right.$ to $\left.25.4 \pm 5.0 \mathrm{~kg} / \mathrm{m}^{2}, \mathrm{p}=0.049\right)$ and from baseline to follow-up $(25.1$ $\pm 4.9 \mathrm{~kg} / \mathrm{m}^{2}$ to $25.6 \pm 4.9 \mathrm{~kg} / \mathrm{m}^{2}, \mathrm{p}=0.022$ ). Waist circumference increased from baseline to post-intervention in this subsample $(82.5 \pm 11.5 \mathrm{~cm}$ to $84.0 \pm 12.5 \mathrm{~cm}$, $\mathrm{p}=0.022)$. 
Twenty-four hour recall data showed no changes in total grain, semi-whole grain, refined grain, fiber, total dairy, full fat dairy, reduced fat dairy, low-fat dairy or saturated fat intake in Heart Start II participants $(p>0.05)$. Energy intake significantly decreased over time (Wilks' Lambda $=0.58, F_{2,16}=5.70, \mathrm{p}=0.014, \eta^{2}=0.42$ ). Decreases in energy intake occurred from baseline to post-intervention (1896.4 \pm $553.3 \mathrm{kcals}$ to $1658.0 \pm 491.1 \mathrm{kcals}, \mathrm{p}=0.009)$. There were no significant changes over time in overall diet quality as measured by the Healthy Eating Index-2010 $(\mathrm{p}=0.39)$.

Mixed between-within ANOVAs comparing Heart Start I and Heart Start II indicated that there was a significant effect of time for HDL-C (Wilks' Lambda = $\left.0.83, F_{2,58}=6.04, \mathrm{p}=0.004, \eta^{2}=0.17\right)$ and total dairy (Wilks' Lambda $=0.90, F_{2,68}=$ 3.93, $\mathrm{p}=0.024, \eta^{2}=0.10$ ) but no significant differences existed between groups. There was also a significant effect of time and group for weight (time: Wilks' Lambda $=$ $0.72, F_{2,60}=11.50, \mathrm{p}<0.001, \eta^{2}=0.28$, group: $\left.F_{1,61}=4.76, \mathrm{p}=0.033, \eta^{2}=0.07\right)$ and BMI (time: Wilks' Lambda $=0.81, F_{2,60}=7.27, \mathrm{p}=0.001, \eta^{2}=0.20$, group: $F_{1,61}=$ 4.90, $\mathrm{p}=0.031, \eta^{2}=0.02$ ). The mean values for weight and BMI were significantly greater in Heart Start II participants compared to Heart Start I participants at each time point. Due to data distribution, a mixed between-within analysis could not be performed for whole grains.

A post-intervention survey revealed that nearly $80 \%$ of participants noticed the messages. Seventy percent reported that the messages prompted them to choose whole grains, while only $40 \%$ indicated that the messages prompted them to choose low-fat 
dairy. Point-of-selection messaging was the most effective messaging delivery method for both whole grains and low-fat dairy (Figure 1).

\section{DISCUSSION:}

The results of this study demonstrate that population-based POS messaging in campus dining halls is an effective strategy to increase whole grain intake in college students. Improvements in HDL-C were seen. Declines in total dairy intake over time suggest that the focus of interventions should shift from low-fat dairy to total dairy.

Whole grain consumption (as measured by the NCI screener) increased by nearly $40 \%$ from baseline to follow-up. This is supported by the purchasing records, which indicated that percent whole grain consumption doubled during the 6-week intervention. It is also consistent with the findings from pilot testing in the spring of 2012 that showed a $12 \%$ increase in whole grains when messages were displayed in dining halls for one-week (S. Mello, personal communication). Results from this study suggest that sustained messaging is needed to produce lasting behavior change as whole grain consumption returned to baseline levels after the messages were removed. Although increases in whole grain consumption were observed, the mean intake at follow-up still fails to meet recommendations. This is consistent with findings by Ha

et al. ${ }^{20}$ that reported an increase in whole grain consumption in college students after a whole grain intervention embedded in a semester-long nutrition course significantly increased whole grain intake from $0.37 \mathrm{oz}$ to $1.16 \mathrm{oz}$. Despite this increase, whole grain intake after the intervention was $>50 \%$ less than the minimum recommendation of $3 \mathrm{oz}$. Exploratory analyses on Heart Start II participants who received the additional 
text messages indicated that this subgroup had non-significant increases in their whole grain intake. This may be attributed to the small sample size in this subgroup analysis $(n=18)$.

Baseline CHD risk factor prevalence data was similar to previous crosssectional estimates of CHD risk factors in this age group ${ }^{12-14,44}$. Despite this documented presence of risk factors in college students, there is a lack of research assessing the impact of nutrition interventions on CHD risk factors in college students. Spinler et al. ${ }^{19}$ reported no changes in total fat, saturated fat or plasma cholesterol concentrations over a 3-month period following a nutrition and cardiovascular disease education in pharmacy students. Although there were no changes in LDL-C in the present study, there were improvements in HDL-C and low HDL-C was the most prevalent risk factor in this sample of college students. The significant increase in HDL-C over time may be explained by the dietary changes, as increases in whole grains have been associated with improvements in HDL-C ${ }^{45}$.

Weight gain during the first year of college is well documented ${ }^{46-51}$. Our sample gained less weight than has been previously reported in this age group ${ }^{49,50}$. Although weight status was not a primary aim of the intervention, the weight gain observed in this population highlights the need for weight gain prevention efforts in this age group. However, interventions focusing on weight must be sensitive to the higher prevalence of disordered eating in this age group ${ }^{52,53}$.

Purchasing records showed a slight increase in non-fat dairy over time but the NCI Screener indicated that total dairy intake decreased over time. Since this screener 
did not allow for the analysis of components of total dairy (reduced fat, low-fat, nonfat) it cannot be determined whether there was a shift to low-fat dairy over time. A decrease in total dairy, however, is consistent with previous findings ${ }^{54,55}$ and provides evidence for the need for additional efforts in this age group to prevent further declines in dairy intake. A reduction in dairy intake typically coincides with an increase in SSB as a result of displacement ${ }^{56}$. In this sample, however, SSB consumption significantly decreased along with dairy consumption over time. Decreased consumption of dairy at follow-up may be a function of weight conscious eating behaviors that occur pre-spring break in anticipation of beaches, as dairy is perceived to be "fattening" ${ }^{2,57}$. Similarly, purchasing records at follow-up showed an increase in whole grain consumption, which may be a function of pre-spring break healthier eating.

Feedback on the individual intervention components revealed that POS messaging was the preferred method of messaging. Point-of-selection messaging has previously been shown to be an effective population-based strategy to promote healthy choices in college dining halls ${ }^{58}$. In a dining hall intervention that utilized signs, table tents, flyers and benefit-based messages, college students reported increased awareness of healthy options as the primary reason for selecting healthier choices ${ }^{32}$.

A major strength of this study was the use of multiple measures to assess dietary intake. To the best of our knowledge, this was the first study to use purchasing records to quantify intake in campus dining halls. An additional strength was the use of multiple methods of message delivery. Although previous studies have used text messaging as an intervention delivery method in this age group ${ }^{35-38,59}$, this was the 
first to use text messages to target dietary choices known to have a positive impact on CHD risk.

Despite these strengths, there were some limitations. The majority of the sample was female and Caucasian, limiting the extent to which results can be generalized to other populations. The use of purchasing records as a proxy for consumption also has limitations. Items were chosen that dining services reported as having minimal waste but plate waste could not be accounted for. Another limitation was the lack of a primary measure for low-fat dairy.

Overall, findings from this study indicate that a population-based nutrition intervention was effective in increasing whole grain intake in college students. Future research should focus on implementing population-based approaches to promote healthy eating on college campuses as cost-effective ways to guide students in making better dietary choices.

\section{SO WHAT? Implications for Health Promotion Practitioners and Researchers}

\section{What is already known on this topic?}

Typical diets consumed by college students fail to meet recommendations for whole grains and exceed saturated and total fat recommendations. These dietary choices negatively impact CHD risk factors. Population-based intervention strategies are needed to address the high prevalence of CHD risk factors in this overlooked age group. 
What does this article add?

Findings from this study demonstrate that relatively small environmental changes such as POS messaging in campus dining halls can positively impact dietary intake and improve CHD risk factors in college students.

What are the implications for health promotion practice or research?

College campuses provide an ideal setting to implement population-based approaches to promote healthier dietary choices. Targeting young adults at a point in their lives when lifestyle choices are being made presents an opportunity to influence lifelong eating habits and improve CHD risk factors in this population. A concerted effort from health professionals, policy makers, dining hall managers and on-campus restaurant owners is needed to create an environment that promotes the adoption of lifelong healthy behaviors. 


\section{References:}

1. Centers for Disease Control and Prevention.National Center for Health Statistics. Health, United States, 2010. Available from:

http://www.cdc.gov/nchs/data/hus/hus10.pdf. Accessed June 22, 2011.

2. Third Report of the National Cholesterol Education Program (NCEP) Expert

Panel on Detection, Evaluation, and Treatment of High Blood Cholesterol in Adults (Adult Treatment Panel III) final report. Circulation. Dec 17 2002;106(25):3143-3421.

3. The Seventh Report of the Joint National Committee on Prevention, Detection, Evaluation, and Treatment of High Blood Pressure. In: National Heart L, and Blood Institute, ed: National Institutes of Health; 2004:1-104.

4. Centers for Disease Control and Prevention. National Center for Health Statistics. Health, United States, 2008 with Special Feature on the Health of Young Adults; 2008. Available from: http://www.cdc.gov/nchs/data/hus/hus08.pdf. Accessed June 22, 2011.

5. Camhi SM, Katzmarzyk PT. Tracking of cardiometabolic risk factor clustering from childhood to adulthood. Int J Pediatr Obes. Apr 2010;5(2):122-129.

6. Stampfer MJ, Hu FB, Manson JE, Rimm EB, Willett WC. Primary prevention of coronary heart disease in women through diet and lifestyle. $N$ Engl J Med. Jul 6 2000;343(1):16-22.

7. Lloyd-Jones DM, Hong Y, Labarthe D, et al. Defining and setting national goals for cardiovascular health promotion and disease reduction: the American Heart Association's strategic Impact Goal through 2020 and beyond. Circulation. Feb 2 2010;121(4):586-613.

8. National Heart, Lung and Blood Institute. Expert Panel on Integrated Guidelines for Cardiovascular Health and Risk Reduction in Children and Adolescents 2012. Available from: http://www.nhlbi.nih.gov/guidelines/cvd_ped/peds_guidelines_full.pdf. Accessed November 10, 2013.

9. Munoz LR, Etnyre A, Adams M, et al. Awareness of Heart Disease Among Female College Students. J Womens Health. Dec 2010;19(12):2253-2259.

10. Kuklina EV, Yoon PW, Keenan NL. Prevalence of coronary heart disease risk factors and screening for high cholesterol levels among young adults, United States, 1999-2006. Ann Fam Med. Jul-Aug 2010;8(4):327-333.

11. Huang TT, Shimel A, Lee RE, Delancey W, Strother ML. Metabolic Risks among College Students: Prevalence and Gender Differences. Metab Syndr Relat Disord. Dec 2007;5(4):365-372.

12. Huang TT, Kempf AM, Strother ML, et al. Overweight and components of the metabolic syndrome in college students. Diabetes Care. Dec 2004;27(12):3000-3001.

13. Morrell JS, Lofgren IE, Burke JD, Reilly RA. Metabolic syndrome, obesity, and related risk factors among college men and women. J Am Coll Health. 2012;60(1):82-89.

14. Fernandes J, Lofgren IE. Prevalence of metabolic syndrome and individual criteria in college students. J Am Coll Health. Jan 2011;59(4):313-321. 
15. Burke JD, Reilly RA, Morrell JS, Lofgren IE. The University of New Hampshire's Young Adult Health Risk Screening Initiative. J Am Diet Assoc. Oct 2009;109(10):1751-1758.

16. Pan Y, Pratt CA. Metabolic syndrome and its association with diet and physical activity in US adolescents. J Am Diet Assoc. Feb 2008;108(2):276286; discussion 286.

17. Berenson GS, Srinivasan SR, Bao W, Newman WP, 3rd, Tracy RE, Wattigney WA. Association between multiple cardiovascular risk factors and atherosclerosis in children and young adults. The Bogalusa Heart Study. $N$ Engl J Med. Jun 4 1998;338(23):1650-1656.

18. Stary HC. Evolution and progression of atherosclerotic lesions in coronary arteries of children and young adults. Arteriosclerosis. Jan-Feb 1989;9(1 Suppl):I19-32.

19. Spinler SA, de Denus S, Earl G, Cheng JW. Plasma cholesterol concentrations, dietary fat intake, and cholesterol intake in pharmacy students. J Am Pharm Assoc (2003). Sep-Oct 2003;43(5):590-595.

20. Ha EJ, Caine-Bish N. Interactive introductory nutrition course focusing on disease prevention increased whole-grain consumption by college students. $J$ Nutr Educ Behav. Jul-Aug 2011;43(4):263-267.

21. Rose N, Hosig K, Davy B, Serrano E, Davis L. Whole-grain intake is associated with body mass index in college students. J Nutr Educ Behav. MarApr 2007;39(2):90-94.

22. Anderson JW, Hanna TJ, Peng X, Kryscio RJ. Whole grain foods and heart disease risk. J Am Coll Nutr. Jun 2000;19(3 Suppl):291S-299S.

23. Grundy SM, Denke MA. Dietary influences on serum lipids and lipoproteins. $J$ Lipid Res. Jul 1990;31(7):1149-1172.

24. Mustad VA, Ellsworth JL, Cooper AD, Kris-Etherton PM, Etherton TD. Dietary linoleic acid increases and palmitic acid decreases hepatic LDL receptor protein and mRNA abundance in young pigs. J Lipid Res. Nov 1996;37(11):2310-2323.

25. Fernandez ML, West KL. Mechanisms by which dietary fatty acids modulate plasma lipids. J Nutr. Sep 2005;135(9):2075-2078.

26. Kuo P, Weinfeld M, Loscalzo J. Effect of membrane fatty acyl composition on LDL metabolism in Hep G2 hepatocytes. Biochemistry. Jul 17 1990;29(28):6626-6632.

27. Anderson JW, Hanna TJ. Whole grains and protection against coronary heart disease: what are the active components and mechanisms? Am J Clin Nutr. Sep 1999;70(3):307-308.

28. Goldstein JL, Brown MS. Regulation of Low-Density-Lipoprotein Receptors Implications for Pathogenesis and Therapy of Hypercholesterolemia and Atherosclerosis. Circulation. Sep 1987;76(3):504-507.

29. Theuwissen E, Mensink RP. Water-soluble dietary fibers and cardiovascular disease. Physiol Behav. May 23 2008;94(2):285-292.

30. U.S. Department of Commerce USCB. School Enrollment. Available at: http://www.census.gov/hhes/school/data/cps/2011/tables.html. Accessed January 28, 2012. 
31. Spencer L. Results of a heart disease risk-factor screening among traditional college students. J Am Coll Health. May 2002;50(6):291-296.

32. Peterson S, Duncan DP, Null DB, Roth SL, Gill L. Positive changes in perceptions and selections of healthful foods by college students after a shortterm point-of-selection intervention at a dining hall. J Am Coll Health. MarApr 2010;58(5):425-431.

33. Freedman MR, Connors R. Point-of-Purchase Nutrition Information Influences Food-Purchasing Behaviors of College Students: A Pilot Study (Reprinted from American Dietetic Association, vol 110, pg 1222-1226, 2010). J Am Diet Assoc. May 2011;111(5):S42-S46.

34. Driskell JA, Schake MC, Detter HA. Using Nutrition Labeling as a Potential Tool for Changing Eating Habits of University Dining Hall Patrons. J Am Diet Assoc. Dec 2008;108(12):2071-2076.

35. Mason M, Benotsch EG, Way T, Kim H, Snipes D. Text Messaging to Increase Readiness to Change Alcohol Use in College Students. J Prim Prev. Oct 102013.

36. Bicard DF, Lott V, Mills J, Bicard S, Baylot-Casey L. Effects of text messaged self-monitoring on class attendance and punctuality of at-risk college student athletes. J Appl Behav Anal. Spring 2012;45(1):205-210.

37. Obermayer JL, Riley WT, Asif O, Jean-Mary J. College smoking-cessation using cell phone text messaging. J Am Coll Health. Sep-Oct 2004;53(2):71-78.

38. Napolitano MA, Hayes S, Bennett GG, Ives A, Foster GD. Using Facebook and Text Messaging to Deliver a Weight Loss Program to College Students. Obesity (Silver Spring). Apr 242012.

39. National Cancer Institute. Dietary Screener Questionnaire. Available from: http://appliedresearch.cancer.gov/studies/nhanes/dietscreen/. Accessed May 25, 2012.

40. Casey PH, Goolsby SL, Lensing SY, Perloff BP, Bogle ML. The use of telephone interview methodology to obtain 24-hour dietary recalls. J Am Diet Assoc. Nov 1999;99(11):1406-1411.

41. Dwyer J, Picciano MF, Raiten DJ, Comm S. Collection of food and dietary supplement intake data: What We Eat in America-NHANES. J Nutrition. Feb 2003;133(2):590s-600s.

42. Serdula MK, Alexander MP, Scanlon KS, Bowman BA. What are preschool children eating? A review of dietary assessment. Annu Rev Nutr. 2001;21:475498.

43. Hirshberg S LJ, Lofgren I. What do college students want? A qualititative study exploring nutrition language and knowledge. FASEB J. 2012;26:246.243.

44. Huang TT, Harris KJ, Lee RE, Nazir N, Born W, Kaur H. Assessing overweight, obesity, diet, and physical activity in college students. J Am Coll Health. Sep-Oct 2003;52(2):83-86.

45. Behall KM, Scholfield DJ, Hallfrisch J. Lipids significantly reduced by diets containing barley in moderately hypercholesterolemic men. J Am Coll Nutr. Feb 2004;23(1):55-62. 
46. Vella-Zarb RA, Elgar FJ. The 'freshman 5': a meta-analysis of weight gain in the freshman year of college. J Am Coll Health. Sep-Oct 2009;58(2):161-166.

47. Morrow ML, Heesch KC, Dinger MK, Hull HR, Kneehans AW, Fields DA. Freshman 15: fact or fiction? Obesity (Silver Spring). Aug 2006;14(8):14381443.

48. Economos CD, Hildebrandt ML, Hyatt RR. College freshman stress and weight change: differences by gender. Am J Health Behav. Jan-Feb 2008;32(1):16-25.

49. Anderson DA, Shapiro JR, Lundgren JD. The freshman year of college as a critical period for weight gain: an initial evaluation. Eat Behav. Nov 2003;4(4):363-367.

50. Levitsky DA, Halbmaier CA, Mrdjenovic G. The freshman weight gain: a model for the study of the epidemic of obesity. Int J Obes Relat Metab Disord. Nov 2004;28(11):1435-1442.

51. Gropper SS, Simmons KP, Gaines A, et al. The freshman 15 -a closer look. $J$ Am Coll Health. Nov-Dec 2009;58(3):223-231.

52. Kelly-Weeder S, Phillips K, Leonard K, Veroneau M. Binge eating and weight loss behaviors of overweight and obese college students. J Am Assoc Nurse Pract. Aug 272013.

53. Unwin BK, Goodie J, Reamy BV, Quinlan J. Care of the college student. AmFam Phys. Nov 1 2013;88(9):596-604.

54. Storey ML, Forshee RA, Anderson PA. Beverage consumption in the US population. J Am Diet Assoc. Dec 2006;106(12):1992-2000.

55. Ranganathan R, Nicklas TA, Yang SJ, Berenson GS. The nutritional impact of dairy product consumption on dietary intakes of adults (1995-1996): the Bogalusa Heart Study. J Am Diet Assoc. Sep 2005;105(9):1391-1400.

56. Rampersaud GC, Bailey LB, Kauwell GP. National survey beverage consumption data for children and adolescents indicate the need to encourage a shift toward more nutritive beverages. J Am Diet Assoc. Jan 2003;103(1):97100.

57. Nolan-Clark DJ, Neale EP, Probst YC, Charlton KE, Tapsell LC. Consumers' salient beliefs regarding dairy products in the functional food era: a qualitative study using concepts from the theory of planned behaviour. BMC Public Health. 2011;11:843.

58. Reed JA, Powers A, Greenwood M, Smith W, Underwood R. Using "point of decision" messages to intervene on college students' eating behaviors. Am J Health Promot. May-Jun 2011;25(5):298-300.

59. Schembre SM, Yuen J. Project TwEATs. A feasibility study testing the use of automated text messaging to monitor appetite ratings in a free-living population. Appetite. Apr 2011;56(2):465-468. 
Table 1: Participant Characteristics

\begin{tabular}{lc}
\hline Baseline Characteristics & \\
\hline & Mean \pm S.D. \\
Age (yrs) & $\underline{\text { \% }}$ \\
& \\
& \\
Gender & 22.4 \\
Male & 77.6 \\
Female & \\
BMI & 76.5 \\
Normal weight $\left(18.5-24.9 \mathrm{~kg} / \mathrm{m}^{2}\right)$ & 18.4 \\
Overweight $\left(25.0-29.9 \mathrm{~kg} / \mathrm{m}^{2}\right)$ & 5.1 \\
Obese (>30.0 kg/m $\left.{ }^{2}\right)$ & \\
Race & 81.4 \\
Caucasian & 2.1 \\
Black or African American & 8.2 \\
Hispanic/Latino & 3.1 \\
Asian & 4.1 \\
Mixed & 1.0 \\
Other & \\
Major & 21.3 \\
Nutrition/kinesiology & 15.3 \\
Allied health (nursing, pharmacy) & 63.4 \\
Other & \\
\hline
\end{tabular}

BMI, body mass index 
Table 2: Heart Start I Anthropometric, Biochemical, Clinical Results

\begin{tabular}{lccc}
\hline Characteristics & $\begin{array}{c}\text { Baseline } \\
(\mathbf{n = 6 3})\end{array}$ & $\begin{array}{c}\text { Post- } \\
\text { Intervention } \\
(\mathbf{n = 6 3})\end{array}$ & $\begin{array}{c}\text { Follow-Up } \\
(\mathbf{n = 6 3})\end{array}$ \\
\hline Weight $(\mathrm{kg})$ & $64.6 \pm 10.4^{\mathrm{a}}$ & $65.7 \pm 11.0^{\mathrm{b}}$ & $65.8 \pm 11.3^{\mathrm{b}}$ \\
Body mass index $\left(\mathrm{kg} / \mathrm{m}^{2}\right)$ & $23.3 \pm 3.2^{\mathrm{a}}$ & $23.6 \pm 3.4^{\mathrm{b}}$ & $23.9 \pm 3.7^{\mathrm{b}}$ \\
Waist circumference $(\mathrm{cm})$ & $77.7 \pm 8.0$ & $78.4 \pm 9.0$ & $78.3 \pm 9.1$ \\
Total cholesterol $(\mathrm{mg} / \mathrm{dL})$ & $152.4 \pm 27.7$ & $158.1 \pm 29.3$ & $159.7 \pm 28.0$ \\
LDL cholesterol $(\mathrm{mg} / \mathrm{dL})$ & $82.9 \pm 21.2$ & $85.0 \pm 22.7$ & $84.3 \pm 22.0$ \\
HDL cholesterol $(\mathrm{mg} / \mathrm{dL})$ & $50.3 \pm 14.5^{\mathrm{a}}$ & $50.8 \pm 12.5^{\mathrm{a}, \mathrm{b}}$ & $54.7 \pm 13.5^{\mathrm{b}}$ \\
Triacylglycerides $(\mathrm{mg} / \mathrm{dL})$ & $97.8 \pm 44.4$ & $107.3 \pm 40.7$ & $107.1 \pm 48.2$ \\
Glucose $(\mathrm{mg} / \mathrm{dL})$ & $87.0 \pm 8.8^{\mathrm{a}}$ & $89.0 \pm 7.3^{\mathrm{b}}$ & $86.0 \pm 6.9^{\mathrm{a}}$ \\
SBP $(\mathrm{mmHg})$ & $115.4 \pm 12.4$ & $115.2 \pm 11.5$ & $113.0 \pm 8.8$ \\
DBP(mmHg) & $70.9 \pm 8.4$ & $72.9 \pm 7.6$ & $71.5 \pm 7.0$ \\
\hline
\end{tabular}

LDL, low-density lipoprotein; HDL, high-density lipoprotein; SBP, systolic blood pressure; DBP, diastolic blood pressure

Different superscripts denote significance $(\mathrm{p}<0.05)$ 
Figure 1: Preferred Intervention Delivery Method

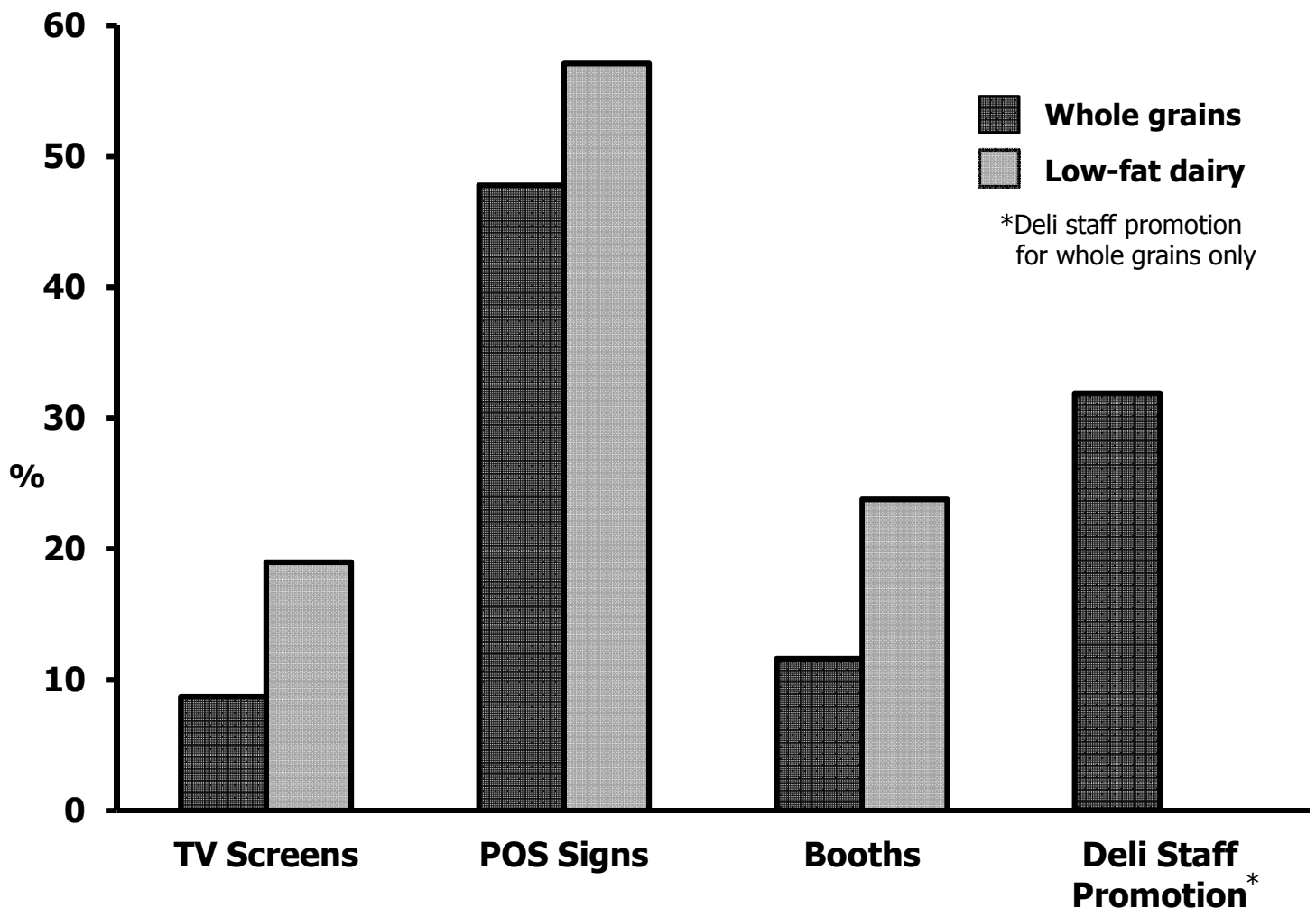

POS, point-of-selection 


\section{APPENDIX 1: EXTENDED METHODS}

\section{Design:}

A quasi-experimental design was used to assess the impact of a populationbased low-fat dairy and whole grain messaging intervention on CHD risk factors.

Baseline and post-intervention assessments were conducted immediately before and after the six-week intervention and the follow-up assessment occurred six months after the baseline assessment.

\section{Study Timeline:}

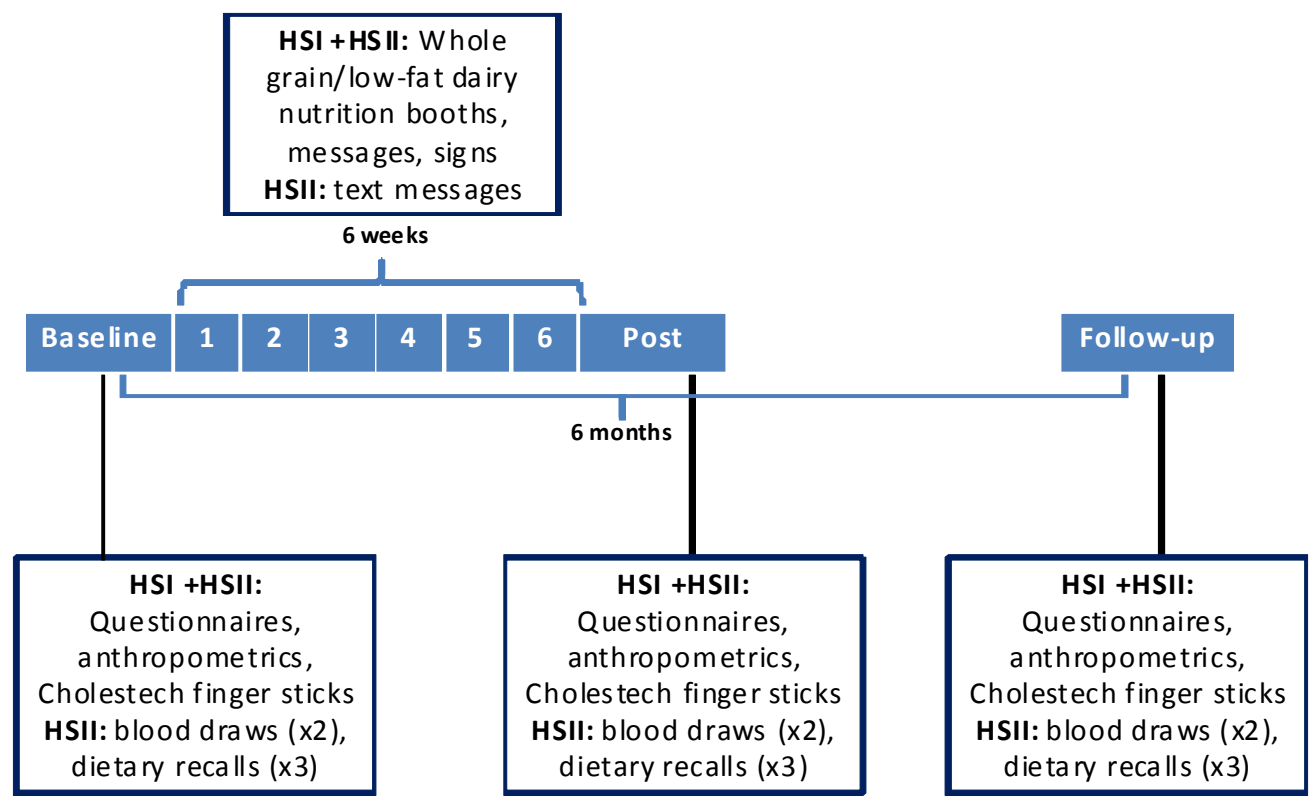

\section{Recruitment:}

URI 101 courses were used to recruit URI students ages 18-24 years with campus meal plans. URI 101 professors were contacted via email to obtain permission for a study staff member to make a class announcement. Nutrition and kinesiology courses were excluded initially but were subsequently included to recruit additional 
participants. Recruiting was also extended to a large introductory general education course (AVS 101).

\section{Study Flow Chart:}

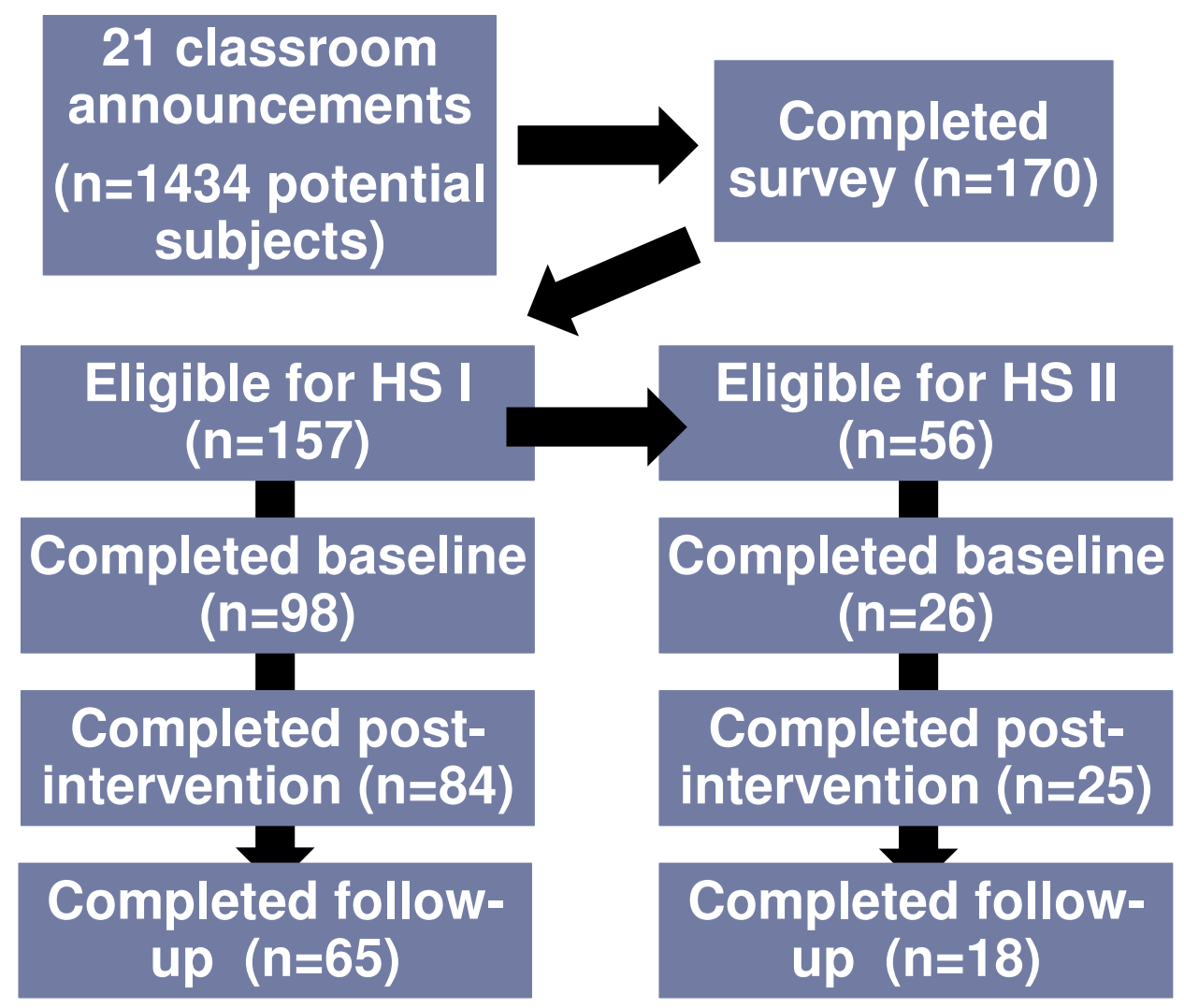

\section{Data Collection:}

\section{Online Surveys}

Students who were interested in participating emailed the study email address and were then sent a link to complete the online surveys before the initial assessment visit. The following surveys were included: Eligibility Screener, Brief Online Consent, Demographics and Health History Questionnaire, NHANES 2009-2010 National Cancer Institute Dietary Screener Questionnaire, International Physical Activity Questionnaire Short Form (1), Weight Related Eating Questionnaire (2), Green Eating 
Survey College Edition and College Environment Perception Survey. Survey data was collected using Survey Monkey (Survey Monkey, Palo Alto, CA) and eligibility was determined. Eligible participants were 18-24 year old males and females with a campus meal plan and a body mass index $\geq 18.5 \mathrm{~kg} / \mathrm{m}^{2}$. Exclusion criteria included being pregnant or lactating, or self-report of one of the following conditions: eating disorder, liver disease, bleeding disorder, diabetes, cancer, or CHD.

\section{Assessment Visits}

Eligible participants were contacted to schedule the $1^{\text {st }}$ assessment visit, which was conducted in Ranger Hall Room 305. At this visit, body mass index was confirmed by measuring height and weight to determine eligibility before the consent

forms were signed (see protocol below). A subsample ( $\mathrm{n}=26$ ) was recruited for Heart Start II, which involved additional measures, based on responses to the green eating stage of change question from the Green Eating Questionnaire (see below). Eligible participants were in the precontemplation, action or maintenance stages of change.

\section{Green eating includes participating in most of the following behaviors:}

- Eating locally grown foods, produce that is in season and a limited amount of processed food

- Consuming foods and beverages that are labeled fair trade certified or certified organic

- Consuming meatless meals weekly and (if consuming animal products) selecting meats, poultry and dairy that do not contain hormones or antibiotics. 


\section{Based on the definition of green eating, which of the following best describes you}

now:

- I do not regularly practice green eating and do not intend to start within the next 6 months (precontemplation)

- I am thinking about practicing green eating within the next 6 months

- I am planning on practicing green eating within the next 30 days

- I regularly practice green eating and have been doing so for less than 6 months (action)

- I regularly practice green eating and have been doing so for 6 months or more (maintenance)

All participants read and signed an informed consent approved by URI's Institutional Review Board. All measurements were obtained at baseline, post-intervention and follow-up:

Anthropometrics

Height was measured to the nearest $0.1 \mathrm{~cm}$ using a Seca 220 stadiometer (Seca Corporation, Hamburg, Germany). Weight was measured to the nearest $0.1 \mathrm{~kg}$ using a calibrated digital Seca 769 scale (Seca Corporation, Hamburg, Germany).

Measurements were taken in duplicate and the average of the two was used for the analysis. Body mass index (BMI) was calculated using the following formula: weight in kilograms/height in meters ${ }^{2}$. Waist circumference was measured in duplicate at the top of the iliac crest upon exhalation to the nearest $0.1 \mathrm{~cm}$ using a Gulick fiberglass, 
non-stretchable tape measure with an attached tensometer (Patterson Medical, Mount Joy, PA). The average of the two values was used for the analysis.

\section{Biochemical}

Following a 12-hour fast, finger sticks were performed on all participants to obtain blood samples for determination of blood lipid and glucose concentrations. Values for LDL-C, TC, TAG, HDL-C and glucose were obtained using Cholestech LDX table-top analyzers (Cholestech, Hayward, CA).

Heart Start II participants also provided two 12-hour fasting venous blood samples on two non-consecutive morning visits in the same week. Blood draws were performed by a trained phlebotomist. Plasma was obtained via centrifugation (Eppendorf Centrifuge 5810, Germany) of whole blood for 20 minutes at 2200 RPM's at $4^{\circ} \mathrm{C}$. The following preservation cocktail was added to the plasma: $0.1 \mathrm{ml}$ of phenylmethylsulfonyl fluoride/100 ml plasma (Roche, Indianapolis, IN), $0.1 \mathrm{ml}$ of sodium azide/100 $\mathrm{ml}$ plasma (Fisher, Fairlawn, NJ) and $0.5 \mathrm{ml}$ of aprotinin/100 $\mathrm{ml}$

plasma (Fisher, Fairlawn, NJ). Samples were stored in a $-80^{\circ} \mathrm{C}$ freezer until analysis.

Total cholesterol concentrations were determined via a Roche Diagnostics Chol kit (Roche, Indianapolis IN) (3). Triacylglycerol concentrations were determined using a Roche/Hitachi Trig/GB kit (Roche, Indianapolis, IN) (4). A Roche/Hitachi Chol kit (Roche, Indianapolis, IN) was used for HDL-C analysis after dextran sulfate and magnesium chloride (Acros Organics, Morris Plains, NJ) were used to precipitate out the apolipoprotein B containing lipoproteins (5). Low-density lipoprotein cholesterol concentrations were calculated using the Friedewald equation (6). 
Plasma glucose concentrations were obtained using an Autokit Glucose (Wako Diagnostics, Richmond, VA). All plates were read in a Biotek ELX 808 plate reader (Biotek, Winooski, VT).

\section{Blood Pressure}

Blood pressure was measured after a 5 minute seated rest period using an automatic blood pressure monitor with arm cuff (Omron HEI-711, Omron Health Care Products, Issaquah, WA). Measurements were re-taken two minutes apart until values were within $2 \mathrm{mmHg}$. The average of the two values in agreement was used for the analysis.

\section{Dietary Intake}

The NHANES 2009-2010 National Cancer Institute Dietary Screener Questionnaire (DSQ) was used to assess intake of fruits and vegetables, dairy/calcium, whole grains/fiber, added sugars, red meat, and processed meat in Heart Start I participants (7). Variables from the survey monkey download were re-named according to the DSQ codebook for the self-administered paper version. Eight-digit food codes were assigned to cereal responses. The SAS program and associated data files were used to analyze the dietary screener questionnaire data file (8). The following variables were calculated from the syntax: predicted fiber (gm) per day, predicted calcium (mg) per day, predicted added sugars (tsp) per day, predicted ounce equivalents of whole grains per day, predicted cup equivalents of dairy per day, predicted cup equivalents of fruits and vegetables (including legumes) per day, 
predicted cup equivalents of fruits and vegetables (including legumes) except French fries per day and predicted added sugars (tsp) from sugar-sweetened beverages.

Purchasing records from dining services were used as a proxy for whole grain and low-fat dairy consumption. Purchasing records were obtained for bread and dairy products that offered a whole grain or low-fat dairy alternative (bread, rolls, breadsticks, English muffins, milk and yogurt) to determine if students selected the whole grain or low-fat dairy option. Purchasing records were obtained at baseline, intervention, post-intervention and 6-month follow-up. According to the whole grain definition used by dining services, items were categorized "whole grain" if the first ingredient was a whole grain. Dairy products were categorized as follows: whole (full fat), low-fat (1\% or $2 \%)$ and nonfat (skim). Average values were calculated for individual items at each time point and were used for the analyses.

Twenty-four hour dietary recalls were collected and analyzed for Heart Start II participants $(\mathrm{n}=26)$ using the multiple pass method in conjunction with the Nutrition Data System for Research (NDS-R) software (University of Minnesota, Minneapolis, MN) version 2012. All participants completed three 24-hour dietary recalls: one inperson and two over the phone on three non-consecutive days (including two weekdays and one weekend day) $(9,10)$. Nasco food models (eNasco, Fort Atkinson, WI) and food amounts booklets were available during the initial in-person 24-hour recall to more accurately estimate portion size (11). Participants were given the booklets after the initial recall for the phone recalls. The mean values of the three recalls provided dietary data for analysis. 
Healthy Eating Index 2010 scores were calculated from the mean values from the three 24-hour recalls for Heart Start II participants to assess diet quality in Heart Start II participants $(\mathrm{n}=26)$. The Healthy Eating Index 2010 reflects the 2010 Dietary Guidelines for Americans (12) and includes twelve dietary components (nine adequacy and three moderation) (13) (Table 1). The University of Minnesota's NDSR "Guide to Creating Variables Needed to Calculate Scores for Each Component of the Healthy Eating Index-2010" was used to calculate scores using NDSR output files (14). 


\section{Table 1: Healthy Eating Index 2010 Components and Scoring}

\begin{tabular}{|c|c|c|c|}
\hline Component & $\begin{array}{l}\text { Optimum } \\
\text { Score }\end{array}$ & $\begin{array}{l}\text { Standard for } \\
\text { maximum score }\end{array}$ & $\begin{array}{l}\text { Standard for minimum } \\
\text { score of zero }\end{array}$ \\
\hline Total Fruit $^{\mathrm{a}}$ & 5 & $\geq 0.8$ cup eq $/ 1,000 \mathrm{kcal}$ & No fruit \\
\hline Whole Fruit ${ }^{\mathrm{b}}$ & 5 & $\geq 0.4$ cup eq $/ 1,000 \mathrm{kcal}$ & No whole fruit \\
\hline Total Vegetables $^{c}$ & 5 & $\geq 1.1$ cup eq $/ 1,000 \mathrm{kcal}$ & No vegetables \\
\hline Greens and Beans $^{c}$ & 5 & $\geq 0.2$ cup eq $/ 1,000 \mathrm{kcal}$ & $\begin{array}{l}\text { No dark-green vegetables } \\
\text { or beans or peas }\end{array}$ \\
\hline Whole Grains & 10 & $\geq 1.5 \mathrm{oz} \mathrm{eq} / 1,000 \mathrm{kcal}$ & No whole grains \\
\hline Dairy $^{\mathrm{d}}$ & 10 & $\geq 1.3$ cup eq $/ 1,000 \mathrm{kcal}$ & No dairy \\
\hline Total Protein Foods ${ }^{e}$ & 5 & $\geq 2.5 \mathrm{oz} \mathrm{eq} / 1,000 \mathrm{kcal}$ & No protein foods \\
\hline Seafood and Plant Proteins ${ }^{\text {ef }}$ & 5 & $\geq 0.8$ oz eq $/ 1,000 \mathrm{kcal}$ & $\begin{array}{l}\text { No seafood or plant } \\
\text { proteins }\end{array}$ \\
\hline Fatty Acids ${ }^{g}$ & 10 & $\begin{array}{l}\text { (PUFAs+MUFAs)/SFAs } \\
>2.5\end{array}$ & (PUFAs+MUFAs)/SFAs $\leq 1.2$ \\
\hline Refined Grains & 10 & $\leq 1.8 \mathrm{oz} \mathrm{eq} / 1,000 \mathrm{kcal}$ & $\geq 4.3 \mathrm{oz} \mathrm{eq} / 1,000 \mathrm{kcal}$ \\
\hline Sodium & 10 & $\leq 1.1 \mathrm{gram} / 1,000 \mathrm{kcal}$ & $\geq 2.0$ grams $/ 1,000 \mathrm{kcal}$ \\
\hline Empty Calories ${ }^{h}$ & 20 & $\leq 19 \%$ of energy & $\geq 50 \%$ of energy \\
\hline
\end{tabular}

${ }^{\mathrm{a}}$ Includes $100 \%$ fruit juice.

${ }^{b}$ Includes all forms except fruit juice.

'Includes any beans and peas not counted as Total Protein Foods.

dIncludes all milk products, such as fluid milk, yogurt, cheese, and fortified soy beverages.

'Beans and peas are included here (and not with vegetables) when the Total Protein Foods standard is otherwise not met.

${ }^{f}$ Includes seafood, nuts, seeds, soy products (other than beverages) as well as beans and peas counted as Total Protein Foods.

'Includes seafood, nuts, seeds, soy products (other than beverages) as well as beans and peas counted as Total Protein Foods.

${ }^{h}$ Calories from solid fats, alcohol, and added sugars; threshold for counting alcohol is >13 g/1000 kcal.

\section{Intervention}

Heart Start I and II participants were exposed to a 6-week intervention, which consisted of benefit-based nutrition messages in campus dining halls. Messages were 
displayed on television monitors and on point-of-selection signs at the deli and dairy stations in both dining halls. Prompts to choose whole grain bread were also verbally provided by the deli station staff in both dining halls. Additionally, nutrition education booths to promote whole grain and low-fat dairy consumption were positioned in a high traffic area outside of Hope. Message and booth content alternated between whole grains and low-fat dairy each week. All URI students who ate at the dining halls were exposed to the intervention.

Intervention materials addressed specific motivators of healthy eating in for students (increased energy, healthy body weight and staying full) from previously conducted focus groups (15). Additionally, Heart Start II participants received the same nutrition message that was displayed on the television monitors in the dining halls each weekday via text message or email, depending on their preference. Google Voice (Google, Mountain View, CA), a web-based application, was used to deliver text messages.

Analysis

Sample Size

$\mathrm{G}^{*}$ Power version 3.1.2 was used to calculate sample size. Sample size calculations were performed based on expected changes in LDL-C from a similar study with an effect size of 0.61 (16). Required sample size was determined to be 23 , with alpha set at 0.05 to achieve statistical power at the 0.80 level.

Descriptive statistics were performed and skewness and kurtosis were examined to determine data distribution. Continuous variables were expressed as 
mean \pm standard deviation and categorical variables were expressed as frequencies. Predicted fiber (gm) per day, predicted added sugars (tsp) per day, total servings of low-fat dairy, LDL-C and BMI were log transformed. Predicted calcium (mg) per day, predicted cup equivalents of fruits and vegetables (including legumes) except French fries per day and TAG were square root transformed. Predicted ounce equivalents of whole grains per day, total servings of semi-whole grains, total servings of fiber, total servings of insoluble fiber, total servings of reduced fat dairy, \% kcals from alcohol, predicted added sugars (tsp) from sugar-sweetened beverages and glucose were analyzed using non-parametric tests.

Repeated measures analysis of variance was used to determine if there were significant differences over time. Mixed between-within analysis of variance assessed differences between groups over time. Physical activity was included as a covariate as appropriate. Statistical significance was set at $\mathrm{p}<0.05$ for all tests. 
References:

1. Craig CL, Marshall AL, Sjostrom M, Bauman AE, Booth ML, Ainsworth BE, Pratt M, Ekelund U, Yngve A, Sallis JF, et al. International physical activity questionnaire: 12-country reliability and validity. Med Sci Sports Exerc. 2003; 35(8): 1381-95.

2. Schembre S, Greene G, Melanson K. Development and validation of a weightrelated eating questionnaire. Eat Behav. 2009; 10(2): 119-24.

3. Allain CC, Poon LS, Chan CS, Richmond W, Fu PC. Enzymatic determination of total serum cholesterol. Clin Chem. 1974; 20(4): 470-5.

4. Kohlmeier M. Direct enzymic measurement of glycerides in serum and in lipoprotein fractions. Clin Chem. 1986; 32(1 Pt 1): 63-6.

5. Warnick GR, Benderson J, Albers JJ. Dextran sulfate-Mg2+ precipitation procedure for quantitation of high-density-lipoprotein cholesterol. Clin Chem. 1982; 28(6): 1379-88.

6. Friedewald WT, Levy RI, Fredrickson DS. Estimation of the concentration of low-density lipoprotein cholesterol in plasma, without use of the preparative ultracentrifuge. Clin Chem. 1972; 18(6): 499-502.

7. National Cancer Institute. Dietary Screener Questionnaire. 2010. Available from:

http://appliedresearch.cancer.gov/studies/nhanes/dietscreen/questionnaires.htm 1. Accessed May 25, 2012.

8. National Cancer Institute. Dietary Screener Questionnaire and SAS Programs. 2010. Available from:

http://appliedresearch.cancer.gov/studies/nhanes/dietscreen/questionnaires.htm 1. Accessed October 14, 2013.

9. Casey PH, Goolsby SL, Lensing SY, Perloff BP, Bogle ML. The use of telephone interview methodology to obtain 24-hour dietary recalls. J Am Diet Assoc. 1999; 99(11): 1406-11.

10. Dwyer J, Picciano MF, Raiten DJ, Comm S. Collection of food and dietary supplement intake data: What We Eat in America-NHANES. J Nutr. 2003; 133(2): 590s-600s.

11. Serdula MK, Alexander MP, Scanlon KS, Bowman BA. What are preschool children eating? A review of dietary assessment. Annu Rev Nutr. 2001; 21: 475-98.

12. The U.S. Department of Health and Human Services and the U.S. Department of Agriculture. Dietary Guidelines for Americans 2010.

13. Guenther PM, Casavale KO, Reedy J, Kirkpatrick SI, Hiza HA, Kuczynski KJ, Kahle LL, Krebs-Smith SM. Update of the Healthy Eating Index: HEI-2010. J Acad Nutr Diet. 2013; 113(4): 569-80.

14. University of Minnesota, Nutrition Data System for Research. Guide to Creating Variables Needed to Calculate Scores for Each Component of the Healthy Eating Index-2010, 2013.

15. Hirshberg S LJ, Lofgren I. What do college students want? A qualititative study exploring nutrition language and knowledge. FASEB J. 2012; 26: 246.3. 
16. Van Horn L, Emidy, L.A., Liu, K., Liao, Y., Ballew, C., King, J., Stamler, J. . Serum Lipid Response to a Fat-Modified, Oatmeal-Enhanced Diet. Preventive Medicine. 1988; 17: 377-386. 


\section{HOW $\bigcirc$ HEALTHY ARE YOU?}

-Is your diet heart healthy?

-Do you know your cholesterol, triglyceride, and glucose levels?

-Do you know your blood pressure?
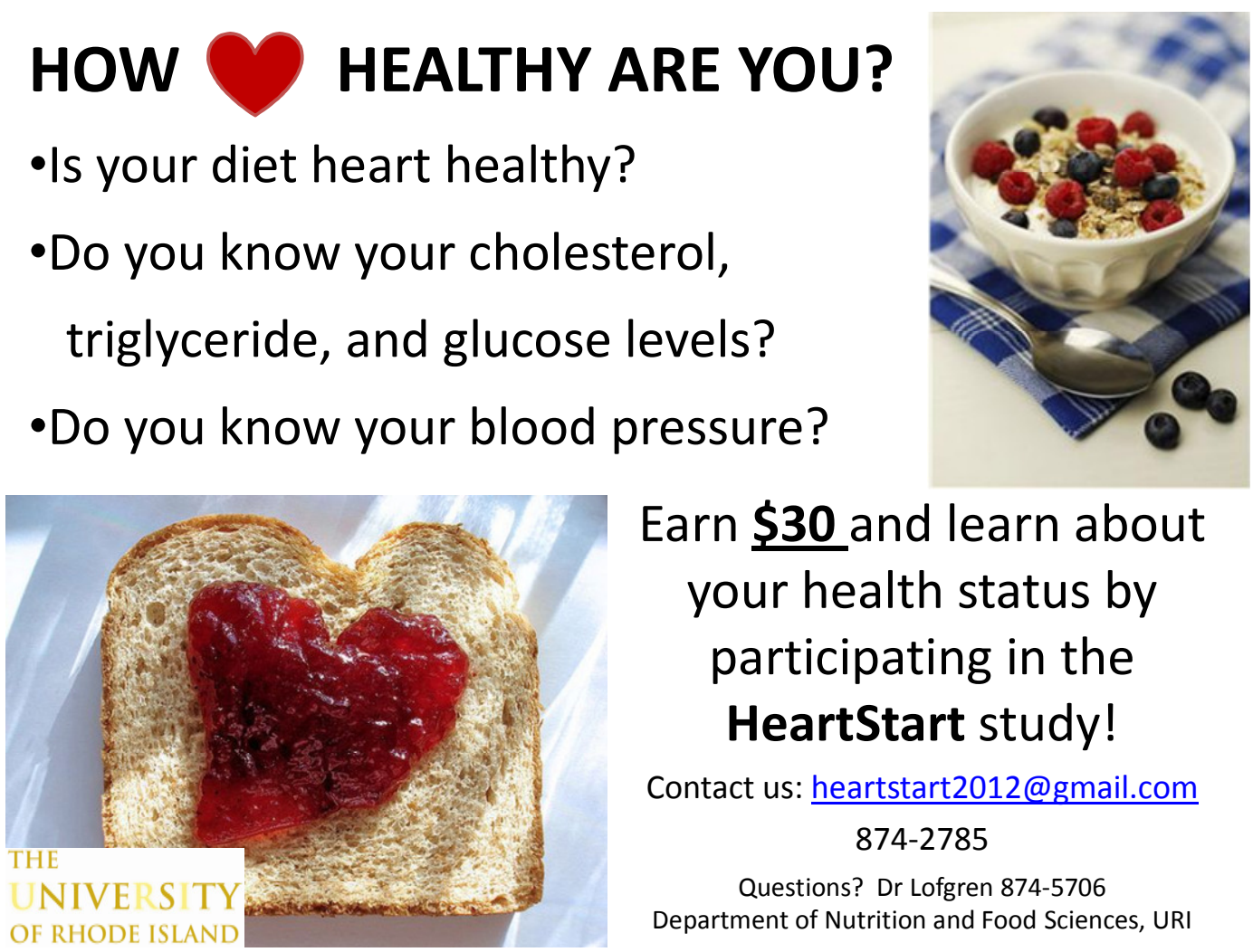

Earn $\$ \mathbf{3 0}$ and learn about your health status by participating in the HeartStart study!

Contact us: heartstart2012@gmail.com

874-2785

Questions? Dr Lofgren 874-5706

Department of Nutrition and Food Sciences, URI 


\section{APPENDIX 3: CONSENT FORM}

The University of Rhode Island

Department of Nutrition and Food Sciences

301 Ranger Hall

HeartStart I

\section{CONSENT FORM FOR RESEARCH}

You have been invited to take part in a research project described below. The researcher will explain the project to you in detail. You should feel free to ask questions. If you have more questions later, Dr. Ingrid Lofgren (401-874-5706 or ingridlofgren@uri.edu) or Jennifer Arts (401-874-2785 or jarts@my.uri.edu),will discuss them with you. You must be 18-24 years old, have a URI meal plan, and have a body mass index $\geq 18.5 \mathrm{~kg} / \mathrm{m}^{2}$ to be in this research project. You are not eligible for this study if you have diabetes (Type 1 or Type II), cancer, coronary heart disease, liver disease, a bleeding disorder, are pregnant or lactating, have disordered eating or any health conditions that may influence energy balance, or if you are on lipidlowering medication. If your body mass index is $<18.5 \mathrm{~kg} / \mathrm{m}^{2}$ you will be referred to health services.

Description of the project:

The purpose of the study is to determine if a campus-wide dietary intervention will improve health status by decreasing coronary heart disease risk factors in college students. The intervention will consist of nutrition messages and education materials displayed around campus.

What will be done:

All students with meal plans will be exposed to the intervention in the dining halls. The study will involve the completion of questionnaires, two brief assessment visits, and a follow-up visit in Ranger Hall. If you decide to take part in this study here is what will happen:

\section{Baseline Assessment:}

Day prior to your first assessment visit (overnight)

- For the twelve hours prior to the first assessment visit, you will be asked to refrain from eating or drinking anything except for water. For example, if your screening visit is scheduled for 8 am on a Tuesday, you will be asked to not eat or drink anything (except for water) after $8 \mathrm{pm}$ on Monday evening. We encourage you to drink as much water as you would like. 
First assessment visit (approximately 30 minutes)

- Your height, weight, waist circumference and blood pressure will be measured.

- A finger prick will be performed to collect a few drops of blood for analysis of blood lipids and glucose.

\section{Month Post-Intervention Assessment:}

Prior to your second assessment visit (approximately 30 minutes)

- You will complete online questionnaires to assess dietary intake, eating behaviors, your college environment and physical activity.

Day prior to your second assessment visit (overnight)

- As with the day prior to the first assessment visit, you will be asked to refrain from eating or drinking anything except for water twelve hours prior to the second assessment visit.

Second assessment visit (approximately 30 minutes)

- Your height, weight, waist circumference and blood pressure will be measured.

- A finger prick will be performed to collect a few drops of blood for analysis of blood lipids and glucose.

- You will receive $\$ 20$ upon completion of this visit.

\section{Month Follow-Up Assessment:}

Prior to your follow-up visit (approximately 30 minutes)

- You will complete online questionnaires to assess dietary intake, eating behaviors, your college environment and physical activity.

Follow-up visit (approximately 30 minutes)

- Your height, weight, waist circumference and blood pressure will be measured.

- A finger prick will be performed to collect a few drops of blood for analysis of blood lipids and glucose.

- You will receive $\$ 10$ upon completion of this visit.

Risks or discomfort:

There are no known risks for the completion of questionnaires and the measurement of height, weight, waist circumference and blood pressure. Even though experienced personnel will obtain the blood samples there is a chance of discomfort from the finger stick.

Benefits of this study:

This study will improve understanding of behavioral and environmental factors that influence coronary heart disease risk and obesity. The direct benefits to you include 
increasing your dietary knowledge and learning about your health status. You will receive the results from your assessment visits (height, weight, body mass index, waist circumference, blood lipids and glucose).

\section{Confidentiality:}

Your participation in this study is confidential. None of the information will identify you by name. All records will be stored in a locked office that is only accessible to study personnel.

In case there is any injury to the subject:

If this study causes you any injury, you should notify Dr. Ingrid Lofgren at 401-8745706 or ingridlofgren@uri.edu. You may also contact the office of the Vice President for Research, 70 Lower College Road, University of Rhode Island, Kingston, Rhode Island, telephone: 401-874-4328.

\section{Decision to quit at any time:}

The decision to take part in this study is up to you. You do not have to participate. If you decide to take part in the study, you may quit at any time. If you wish to quit, simply inform Jennifer Arts at 401-874-2785 or jarts@ my.uri.edu or Dr. Ingrid Lofgren at 401-874-5706 or ingridlofgren@uri.edu of your decision.

Rights and Complaints:

If you are not satisfied with the way this study is performed, you may discuss your complaints with Dr. Ingrid Lofgren, anonymously, if you choose. In addition, if you have questions about your rights as a research participant, you may contact the office of the Vice President for Research, 70 Lower College Road, Suite 2, University of Rhode Island, Kingston, Rhode Island, telephone: (401) 874-4328.

You have read the consent form. Your questions have been answered. Your signature on this form means that you understand the information and you agree to participate in this study.

Signature of Participant

Typed/printed Name

Date
Signature of Researcher

Typed/printed name

Date 
I consent to be contacted for future research related to this project or other projects.

Signature of Participant

Typed/printed Name

Date

Please sign both consent forms, keeping one for yourself
Signature of Researcher

Typed/printed name

Date 


\section{Subject ID\#}

Date:

Time:

Visit: $\square$ Baseline $\quad \square$ Post-Intervention $\quad \square$ Follow-up

\section{Researcher:}

\section{Questions to ask participant}

1. At what time did you last have something to eat?

a.m. or p.m.

2. At what time did you last have something to drink?

a.m. or p.m.

3. Have you had any caffeine, tobacco, or tobacco products today?

$\square$ Yes $\quad \square$ No

If yes, please have participant explain:

What:

When: a.m. or p.m.

Have you participated in any structured exercise either yesterday or today?

$\square$ Yes $\quad \square$ No

If yes, please have participant explain:

4. Are you currently ill? $\square$ Yes $\square$ No

5. Is there any reason you feel you are unable to participate in testing today? $\square$ Yes $\square$ No

If yes, have participant explain:

6. Please ask participant if there is any additional information they would like to provide to the assessment staff member: 


\section{$\underline{\text { Reasons to Reschedule }}$}

1. If participant has eaten in the last 12 hours.

2. If participant drank something in the last 12 hours (exception water).

3. If participant had any caffeine in the last 12 hours.

4. If the participant is ill.

5. If participant states they are unable to participate today.

- Participant is cleared for the assessment today.

- Participant will need to be rescheduled because 


\section{APPENDIX 5: WHOLE GRAIN AND LOW-FAT DAIRY MESSAGES}

\section{Whole Grain:}

Fill up with fiber! Choose whole grain bread on your sandwich.

Make the switch to whole grain breads and wraps to stay full longer.

Maintain a healthy weight...choose whole grain breads, wraps and pitas.

Need energy? Eat whole grain bread and wraps.

Fiber up! Eat whole grains.

\section{Low-Fat Dairy:}

Maintain a healthy weight...choose low-fat dairy.

Be heart smart...drink low-fat milk.

Trim excess fat without sacrificing taste. Switch to low-fat dairy.

Choose low-fat dairy...your heart will love you.

Make the switch to low-fat dairy to cut unwanted fat. 